\title{
Is warrant really a derivative? \\ Evidence from the Chinese warrant market
}

\author{
Eric C. Chang \\ School of Economics and Finance \\ The University of Hong Kong \\ Pokfulam Road, Hong Kong \\ Email: ecchang@hku.hk \\ Xingguo Luo \\ School of Economics and Finance \\ The University of Hong Kong \\ Pokfulam Road, Hong Kong \\ Email:xgluo@hku.hk \\ Lei Shi \\ HSBC School of Business \\ Peking University \\ University Town, Shenzhen, P. R. China \\ Email: shileianderson@gmail.com \\ Jin E. Zhang ${ }^{1}$ \\ School of Economics and Finance \\ The University of Hong Kong \\ Pokfulam Road, Hong Kong \\ Email: jinzhang@hku.hk
}

First Version: January 2008

This Version: January 2012

Keywords: Warrants; the Chinese warrant market; Option pricing model

JEL Classification Code: G13

\footnotetext{
${ }^{1}$ Corresponding author, Tel: (852) 2859 1033, Fax: (852) 2548 1152. The authors would like to acknowledge helpful comments and suggestions from Charles Cao, Dengshi Huang, Hao Wang and seminar participants at Hai Nan University, South China Normal University, Peking University, 2009 China International Conference in Finance (CICF 2009) in Guangzhou, and 2011 HKU-HKUST-Stanford Conference in Quantitative Finance in Hong Kong. Jin E. Zhang has been supported by a grant from the Research Grants Council of the Hong Kong Special Administrative Region, China (Project No. HKU 7549/09H).
} 


\title{
Is warrant really a derivative? Evidence from the Chinese warrant market
}

\begin{abstract}
This paper studies the Chinese warrant market that has been developed since August 2005. Empirical evidence shows that the market prices of warrants are much higher systematically than the Black-Scholes prices with historical volatility. The prices of a warrant and its underlying asset do not support the monotonicity, perfect correlation and option redundancy properties. The cumulated delta-hedged gains for almost all expired warrants are negative. The negative gains are mainly driven by the volatility risk, and the trading values of the warrants for puts and the market risk for calls. The investors are trading some other risks in addition to the underlying risk.
\end{abstract}




\section{Introduction}

This paper documents the anomaly of the Chinese warrant market that has been developed since August 2005. We find that the market prices of warrants are generally much higher systematically than the Black-Scholes prices and provide evidence that warrants in China in these embryo years could not be effectively replicated by the underlying assets and hence were unlikely to be an effective hedging tool. Therefore, while carrying the same name, warrants in China markets can hardly be viewed as a conventional option-like derivative. The success of the market must be attributed to the possibility that it met economic needs other than hedging and risk management. Particularly, we examine the extent to which the China warrant and underlying prices conform to the one-dimensional diffusion model, study the cumulated gains of a delta-hedged warrant portfolio, and conduct investigation into what economic variables may account for these negative delta-hedging gains. We contribute to the literature by offering a systematic empirical study of the most active warrant derivative market worldwide, which also happens to be the youngest of its kind. This is of no surprise as, in the absence of a short-sale mechanism, arbitrage trading in this market is essentially impossible. The evidence reinforces this fundamental intuition and offers a useful reference to regulatory agencies of other emerging financial markets.

The literature on studying the Chinese warrant market is scarce. Xiong and $\mathrm{Yu}$ (2011) observe bubbles in the market by focusing on put warrants in 2005-2008. They also use the data to test bubble theories and show evidence of the experimental bubble. Wu (2011) further studies the Chinese warrants bubble by using both put and call warrants in 2005-2009. He finds that the bubble size is related to turnover, daily price change, and the total number of warrants outstanding. Powers, Xiao, and Yan (2009) use adjusted Black-Scholes model, jump-diffusion model and constant elasticity of variance model to examine pricing errors in the Chinese warrants. They argue that unique settlement rule is an important factor for the mispricing in the warrants and investors were willing to pay a premium for put warrants to get a convenience yield. 
The methodology of our main empirical tests was proposed and used by Bakshi, Cao and Chen (2000) in which they examine whether or not the one-dimensional diffusion model applies in the S\&P 500 index options market. The one-dimensional diffusion model is also known as the local (deterministic) volatility model and was independently developed by Derman and Kani (1994a, b), Dupire (1994), and Rubinstein (1994). An important implication of one-dimensional diffusion models is that the derivative price depends only on the prices of its underlying assets. Examples of one-dimensional diffusion models include the classical Black and Scholes (1973), Merton (1973), and the Cox and Ross (1976) constant elasticity of variance (CEV) model. Bakshi, Cao and Chen (2000) argue that any one-dimensional diffusion model must satisfy three properties: monotonicity, perfect correlation and redundancy between warrant and its underlying prices. If the prices of a warrant market systematically violate any of the three properties, one may conclude that the one-dimensional diffusion model does not apply in this market. Following the idea, we first test whether the China warrant prices follow the Black-Scholes formula with historical volatility. We then perform comprehensive tests on the monotonic, perfect correlation and redundant relationships between the warrant and the underlying prices for all 30 available expired warrants. We find that the market prices of warrants are much higher systematically than the Black-Scholes prices with historical volatility and document ample evidence that the one-dimensional diffusion model does not apply well in the Chinese warrant market.

Further, we study the cumulated gains of a delta-hedged warrant portfolio by following Bakshi and Kapadia (2003a, b). We find that the cumulated gains are negative for 27 out of 30 expired warrants. While Bakshi and Kapadia (2003a) also document a negative average delta-hedging gain in the S\&P 500 options market, the magnitude of the average gains in the Chinese warrant market is a few hundred times larger than those reported in the U.S. market. The extremely poor hedging performance further confirms the inapplicability conclusion of the one-dimensional diffusion model tests. Moreover, we conduct investigation into what economic variables may account for these daily delta-hedging gains. The regression results suggest that the negative gains are significantly related to the market index return volatility, the underlying stock 
return volatility, the daily trading value of warrants (for puts), and the market risk (for calls).

The split share structure reform of listed companies in China triggered the launch of the Chinese warrant market in 2005. Since the listing of Baosteel warrant (580000), the first of its kind, on August 22, 2005, the China domestic investors have been overwhelmingly passionate about the warrants on equities and the market has made remarkable achievements. According to Goldman Sachs, the total warrant turnover in China's stock exchanges was USD250.5 billion in 2006, compared with USD230.4 billion in Hong Kong and USD124.3 billion in Germany. In 2006 and 2007, the warrant markets in China, Hong Kong and Germany were ranked the top three in the world in terms of trading value and turnover. It is an amazing record since there were only 17 warrants being traded in two exchanges in China at the end of November 2007, compared with 4,394 in Hong Kong and 270,254 in Germany. The Chinese warrant market created top trading volume and turnover with only a handful of different warrants traded.

If trading volume is a proper yardstick, then the record speaks for itself that the development of the China warrant market has been a huge success. Therefore, while failing to be an effective hedging tool, one must admit that these financial assets have met some other important economic demand. One such possibility is the speculative demand. As up to now, equity trading on margin of any form is still prohibited in China. Derivatives enable investors to trade on information that otherwise might be prohibitively expensive to trade on. Call warrants, for example, have characteristics similar to levered positions in the underlying asset. They allow investors to assume the same risk of the underlying asset with a relatively small investment. Likewise, with put warrants, investors can more easily take advantage of negative information about the underlying assets when faced with short-sale constraints. We suspect that facilitating trades on either positive or negative information in a relatively cheap manner could have contributed to the large demand. If it is so, the availability of these new financial instruments might somewhat has enhanced the completeness of the China financial markets.

The overwhelmingly large trading volume and turnover render a systematic study on the Chinese warrant market an important task in its own right. However, what is more important for 
such a study is that China launched the warrant market at a time when short-sales of any financial assets were not allowed in the markets. The lack of such a crucial mechanism makes a low-cost perfect replication of derivatives by other financial assets impossible. As a result, no risk-free arbitrage force arguably exists to exploit any possible mis-alignment between the prices of the warrants and the underlying assets, rendering the possibility that warrants are priced by mechanisms other than those suggested by conventional derivative theories.

However, when a huge speculative demand is present and a cheap risk-free arbitrage mechanism is absent, one still could not entirely eliminate the possibility that the huge trading volume and the extraordinary price volatility exhibited in some trades are simply a manifestation of the resale option theory of bubbles. This idea was first proposed by Harrison and Kreps (1978) and recently applied to the China warrant market by Xiong and Yu (2011). We also observed that some very deep out-of-the-money warrants were created by qualified issuers with a hardly justifiable price and were actively traded by retail investors. Indeed, there were incidents in which securities firms made significant profits by selling "zero value” put warrants to retail investors. The evident is consistent with the claim that a speculative bubble to some extent existed in this embryo market. Perhaps undercurrent forces, market completion enhancement and speculative frenzy have played a role in creating the phenomenal trading volume. This should be an interesting future research issue. It is clear from this study that warrants in general are not redundant assets in the China capital markets as evidence shows that the conditions of the one-dimensional diffusion model were frequently violated and the investors were trading some other risks in addition to the underlying risk.

The remainder of the paper is structured as follows. Section II introduces the history and current situation of the Chinese warrant market. Section III describes the data. Section IV presents empirical results. Section V concludes the paper.

\section{Warrant and the Chinese warrant market}




\subsection{Warrants}

Warrants are the call or put options written by the issuer of underlying securities or by a third party, entitling their holders to purchase (call) or sell (put) the underlying securities from or to the issuer, or collect the price difference by cash settlement, at a predetermined price at any time during a specified period or on a specified expiry date. Hereinafter, unless otherwise specified, warrant refers to call warrant. Warrants can be divided into two categories based on the type of issuers: equity warrants and covered warrants. Equity warrants are issued by the issuers of the underlying stocks (usually the listed companies), whereas covered warrants are issued by an independent third party (usually financial institutions such as investment banks). The detailed differences between equity warrants and covered warrants are listed in Table 1.

\subsection{Overview of the Chinese warrant market}

Warrants were launched in the mainland China financial market as early as the 1990s, not long after China established the stock market. The Da Feile warrant, the first of its kind, was issued in Shanghai in June 1992. During the 1990s, there were 14 warrants in total in the Chinese market. However, the issuance of warrants was abolished later by the regulator due to rampant speculation and market manipulation. The reintroduction and development of Chinese warrant market in 2005 was a result of the split share structure reform of listed companies. For example, Baoshan Iron \& Steel Co. was the first company to issue the warrants as part of a plan to compensate its investors for allowing the companies' non-tradable shares to be listed on the Shanghai Stock Exchange. More specifically, for every 10 shares held, minority shareholders were given 2.2 bonus shares and one warrant giving them the option to buy one share for 4.5 yuan, or about 56 U.S. cents, within a specified time.

Currently all stock trades in the Chinese financial market are settled on the next business day following a transaction, which is called " $\mathrm{T}+1$ ". Only warrants trades are allowed to be settled on the same day of a transaction, and is called " $\mathrm{T}+0$ ". Allowing investors to buy and sell securities on the same day (intraday trading) provides investors with greater flexibility to take advantage of 
short-term swings in security prices. Due to the scarcity of " $\mathrm{T}+0$ " investment instruments, combined with other reasons such as transaction cost and price change limits, Baosteel warrants and all the other subsequent warrants soon became one of the favorite products of Chinese investors.

Until March 14, 2008 (the end of our sample period), 47 warrants have been traded in either the Shanghai or the Shenzhen Stock Exchanges. Among these warrants, 30 were expired, and 17 were still being traded at that point in time. These 47 warrants contain 28 covered warrants and 19 equity warrants. The detailed information for each warrant is listed in the Appendix.

\subsection{The warrant creation mechanism in the Chinese warrant market}

In developed markets like Hong Kong or Germany, all of the standard warrant products adopt the mechanism of "continuous creation" which allows issuers or other qualified institutions to add to the supply of warrants at any time. When launching the second (Wuhan Steel call 580001) and the third (Wuhan Steel put 580999) warrants, Shanghai Stock Exchange (SSE) released the "Notice of Relevant Issues concerning Securities Companies' Creation of Wuhan Steel Warrants", which stated that the securities companies with the innovation pilot qualification of the Securities Association of China are eligible to create new warrants. The warrant creation mechanism has been in place since then. This creation mechanism means that after a warrant is issued in the split share structure reform of listed companies, qualified securities companies (creators) may create warrants with the same specification as the original ones traded in the market. The creation involves writing a new contract and selling it to the market, which increases the supply and stabilizes the price. The creators may cancel the warrant by repurchasing it from the market. For the cancellation, the creator who applies to cancel warrants, upon approval of the SSE, and after buying back a certain amount of warrants, should notify the Shanghai Branch of China Securities Depository and Clearing Corporation Limited (CSDC) to cancel the warrants on the very day and unfreeze the corresponding shares or capital on the next day.

Warrant prices in the Chinese market are usually much higher than their theoretical values. 
This was especially so in the two-year bull market (2006 and 2007). Even a deeply out-of-the-money put could still have a high price. It brings to those securities companies, who are qualified to create warrants, opportunities to make huge profits from the creation of warrants. So far only those securities companies with innovation pilot qualification awarded by the Securities Association of China are qualified to create warrants, and domestic investors call these companies “innovative securities companies” (innovation pilot securities dealers). In this situation, even if the market price of warrants is abnormally high, only these "innovative securities companies” may earn abnormal profit from taking short positions.

\section{Data}

In this section, we introduce the data. The dataset employed in this study is from Wind Info, a leading financial data provider in Mainland China. We use all of the 30 warrants that expired before March 14, 2008. The sample period is from August 22, 2005 to March 14, 2008. The data cover daily warrants closing prices, trading volume and trading value. The data for the underlying stocks and Shanghai Composite Index cover open, high, low and close prices, trading volume and trading value. The time window of the underlying stocks data is one or two years longer than the warrant data for the purpose of computing historical volatility. We use CNY benchmark deposit rates of financial institutions released by the People's Bank of China as the risk-free rate. Note that Bakshi, Cao and Chen (2000) study the S\&P 500 index options market by using intraday data. In the Chinese warrant market, some warrants, especially put warrants, are traded so actively that their trading is forced to be suspended by the exchanges for several hours on certain days, while the underlying stocks are still traded during this period. Due to the time inconsistency in intraday data between the warrants and their underlying stocks, we use daily data.

\subsection{Summary statistics of the Chinese warrant market}

Table 2 shows the average daily trading volume/value of all the 30 expired warrants and their 
underlying stocks during the lifetime of the warrants, the average daily price/time value (market and Black-Scholes), and the daily average volatility in addition. We find that for all of the warrants, except Wanhua HXB1 (580005), the average daily trading volume/value of the warrants is significantly higher than that of their underlying stocks. In some cases, such as Hansteel JTB1 (580003), it can be ten times higher. Market price and time value computed from market price are generally much higher systematically than the Black-Scholes ones. Implied volatility is also significantly higher than historical volatility at $1 \%$ level.

\subsection{A comparison between the market price and the Black-Scholes price}

Figure 1a shows the market prices and Black-Scholes prices with historical volatility of the “typical” warrant, Baosteel JTB1 (580000). The historical volatility on any date is computed as the standard deviation of log stock price returns in a moving window of fixed length. The length of the moving window is determined as the time to expiration of the warrant at its initial trading date. From Figure 1a, we observe that the market prices of warrants are generally much higher than their Black-Scholes prices. This phenomenon is significant for four put warrants: Zhaohang CMP1 (580997), Hualing JTP1 (038003), Zhongji ZYP1 (038006) and Jiafei JTP1 (038008). During the period between the end of May 2007 (“5.30 market crash”1 ) and the beginning of July 2007, as short-term deeply out-of-the-money puts, the values of these four warrants were supposed to be zero. However, their market prices were unreasonably high. In this situation, the “innovative securities companies” (innovation pilot securities dealers), who are qualified to create warrants, made huge arbitrage profit by creating and selling these deeply out-of-the-money put warrants to the market.

Figure 1b shows a comparison between the daily trading value of the warrants and that of their underlying stocks. We find that the daily trading value of the warrants is consistently higher

\footnotetext{
${ }^{1}$ On May 30, 2007, Chinese Ministry of Finance raised the stamp tax from $0.1 \%$ to $0.3 \%$. The unexpected sharp rise of the transaction cost caused the markets to crash in both the Shanghai and Shenzhen stock market. Put warrants were the only instruments in the market for investors to take short position under the short-sale constraints. So the investors became passionate in trading those existing put warrants at that time, such as the four put warrants mentioned before.
} 
than that of their underlying stocks. We offer the following explanations: (1) In order to take advantage of short-term swings of the asset price, domestic investors prefer products that have " $\mathrm{T}+0$ " mechanism which mentioned in section II. This motivates investors to trade warrants actively. According to a statistics by the Shanghai Stock Exchange, 80\% of the warrant trading volume was induced by the " $\mathrm{T}+0$ ” mechanism. (2) There is no stamp tax on warrant trading, whereas $0.1 \%-0.3 \%$ stamp tax is imposed on stock trading. The low transaction cost is another attractive aspect of warrant trading. (3) Warrants have different daily price fluctuation limits from underlying stocks. While the limits for daily price changes of stock trading are $10 \%$ up or down, the fluctuation scale of warrants can be much wider than that of the underlying stocks.

Figure 2 shows the market prices, Black-Scholes prices and trading value of Zhaohang CMP1 (580997) as an example of the four put warrants mentioned above. They were heavily over-priced a few months before the maturity dates. It is interesting to observe that their market prices are highly correlated with their trading values. This phenomenon indicates that the over-pricing of the four put warrants was driven by the frenetic speculation in the market. We will come back to this point when presenting our regression results of delta-hedged gains.

3.3. A comparison between time values computed from the market price and that from the Black-Scholes price

For those deeply in-the-money call warrants, such as Wanhua HXB1 (580005), Yager QCB1 (580006), Yili CWB1 (580009), Qiaocheng HQC1 (031001) and Shenfa SFC1 (031003), their market prices look very close to their Black-Scholes prices, due to their large intrinsic values. The intrinsic value for European options (warrants) is defined as $\max \left(S-K e^{-r \tau}, 0\right)$ for call, and $\max \left(K e^{-r \tau}-S, 0\right)$ for put, where $S$ is the underlying stock price, $K$ is the strike price, $r$ is the risk-free rate, and $\tau$ is the time to maturity. In order to observe the difference between market and Black-Scholes prices more clearly, we should study their time values. The time value of a warrant is defined as the difference between its market (Black-Scholes) price and its intrinsic 
value.

Figure 3a shows the time values computed from the market and Black-Scholes prices of the “typical” warrant, Zhonghua CWB1 (580011). We observe that the time value of call warrants computed from market price is higher than that computed from the Black-Scholes price. Sometimes certain call warrants have negative time values, which indicates that they are underpriced at this moment. The time value of put warrants computed from market price is usually much higher than that computed from the Black-Scholes price.

\subsection{A comparison between implied volatility and historical volatility}

To further quantify the misprice of a warrant, we compare its implied volatility with its historical volatility. Figure 3b shows a comparison between implied volatilities and historical volatilities of the "typical” warrant, Zhonghua CWB1 (580011). For some warrants, such as Yili CWB1 (580009) and Zhonghua CWB1 (580011), the implied volatility cannot be computed on certain dates due to the fact that their market prices are lower than their intrinsic values on these days.

From Figure 3b, we observe that the implied volatility of call warrants is around $100 \%-300 \%$, which is much higher than historical volatility (around 40\%). The implied volatility of put warrants is even higher, up to $1000 \%$, increasing dramatically as the maturity date approaches. This is because the deeply out-of-the-money put warrants were still traded with a certain price a couple days before the maturity dates.

\section{Empirical Results}

In this section, we empirically examine violations of market observations to the predictions of one-dimensional diffusion models, compute the excess gain of a delta-hedged warrant, and explore the hidden factors that drive the dynamics of the gain. A delta-hedged portfolio is: (1) a long call position, hedged by a short position in the underlying stock, or (2) a long put position, 
hedged by a long position in the underlying stock, with the net investment earning the risk-free rate. The methodologies used mainly follow that of Bakshi, Cao and Chen (2000), and Bakshi and Kapadia (2003a).

Before presenting empirical results, we first review the one-dimensional model and its properties. Assume that the price of underlying asset, $S_{t}$, follows a one-dimensional diffusion process as follows (for simplicity, here we assume that underlying assets do not pay dividend):

$$
d S_{t}=\mu(S, t) S_{t} d t+\sigma(S, t) S_{t} d B_{t}, \quad t \geq 0
$$

where the drift $\mu(S, t)$ and the volatility $\sigma(S, t)$ are deterministic functions of $S_{t}$ and $t, B_{t}$ is a standard Brownian motion. All the option pricing models, which are built on the underlying prices with one-dimensional diffusion process, must have the following three properties: the monotonicity property, the perfect correlation property and the option redundancy property. The proof of the monotonicity property is provided by Bergman, Grundy, and Wiener (1996). They show that if the underlying asset price process is a one-dimensional diffusion process, as well as in certain restricted stochastic volatility models, the option's Delta is bounded by the infimum and supremum of its Delta at maturity, which means $0 \leq \frac{\partial C}{\partial S} \leq 1$ for Call and $-1 \leq \frac{\partial P}{\partial S} \leq 0$ for Put. Moreover, if the option's payoff is convex (concave), the option's price is a convex (concave) function of the underlying asset's price. The perfect correlation property is determined by the sole source of stochastic variation for all options in a one-dimensional diffusion model. For the option redundancy property, we know that an option can always be exactly dynamically replicated by the underlying asset and a risk-free bond. The excess gain of a delta-hedged option is zero.

In order to facilitate our understanding of the nature of the excess gain generated by a delta-hedged option, now we present a generic two-factor model. Assuming the underlying asset follows the same diffusion process in equation (1), but investors are trading an additional risk factor, denoted by $X(t)$ in the warrant market. For example, in the stochastic volatility models, including Heston (1993) square-root model, $X(t)$ is a stochastic volatility. The new factor 
follows the process

$$
d X_{t}=\theta d t+\eta d B_{t}^{X}
$$

where $B_{t}^{X}$ is a standard Brownian motion that is correlated with $B_{t}$ in the underlying process with coefficient $\rho$. The warrant price, $C(S, X, t)$, is then a function of $S_{t}, X_{t}$ and $t$. By Ito’s lemma, we have a process for the warrant price

$$
\begin{aligned}
d C= & \left.\frac{\partial C}{\partial t}+\mu S \frac{\partial C}{\partial S}+\theta \frac{\partial C}{\partial X}+\frac{1}{2} \sigma^{2} S^{2} \frac{\partial^{2} C}{\partial S^{2}}+\frac{1}{2} \eta^{2} \frac{\partial^{2} C}{\partial X^{2}}+\sigma S \eta \rho \frac{\partial^{2} C}{\partial S \partial X}\right) d t \\
& +\sigma S \frac{\partial C}{\partial S} d B_{t}+\eta \frac{\partial C}{\partial X} d B_{t}^{X} .
\end{aligned}
$$

A delta-hedged portfolio is defined as $\Pi=C-\Delta S$, where $\Delta \equiv \frac{\partial C}{\partial S}$. The excess gain of the delta-hedged portfolio is

$$
\begin{aligned}
d \Pi-r \Pi d t= & \left(\frac{\partial C}{\partial t}+r S \frac{\partial C}{\partial S}+\theta \frac{\partial C}{\partial X}+\frac{1}{2} \sigma^{2} S^{2} \frac{\partial^{2} C}{\partial S^{2}}+\frac{1}{2} \eta^{2} \frac{\partial^{2} C}{\partial X^{2}}+\sigma S \eta \rho \frac{\partial^{2} C}{\partial S \partial X}-r C\right) d t \\
& +\eta \frac{\partial C}{\partial X} d B_{t}^{X} .
\end{aligned}
$$

The risk in the portfolio depends only on the risk in the process of $X_{t}$. For example, investor trade volatility risk as noted by Bakshi and Kapadia (2003a). The cumulated gain from $t$ to $t+\tau$, denoted by $\pi(t, t+\tau)$ is given by

$$
\pi(t, t+\tau) \equiv C_{t+\tau}-C_{t}-\int_{t}^{t+\tau} \Delta d S-\int_{t}^{t+\tau} r(C-\Delta S) d u
$$

If there is only one factor ( $B_{t}$ in stock price process) traded in the derivatives market, then $\pi(t, t+\tau)$ must be zero. Moreover, if $\pi(t, t+\tau)$ is significantly nonzero, we may conclude that there is at least one more additional risk factor $X_{t}$ traded in this market. In section 4.3, we will use the discrete form of equation (4) to compute the delta-hedged gains.

\subsection{Testing the monotonicity property}

Following Bakshi, Cao and Chen (2000), we divide the violations between warrant price changes and underlying price changes into four main categories: 
Type I violation: $\quad \Delta S \times \Delta C<0 \Leftrightarrow \Delta S>0$ and $\Delta C<0$, or $\Delta S<0$ and $\Delta C>0$; $\Delta S \times \Delta P>0 \Leftrightarrow \Delta S>0$ and $\Delta P>0$, or $\Delta S<0$ and $\Delta P<0$.

Type II violation: $\Delta S \neq 0$, but $\Delta C=0$; $\Delta S \neq 0$, but $\Delta P=0$.

Type III violation: $\Delta S=0$, but $\Delta C \neq 0$; $\Delta S=0$, but $\Delta P \neq 0$.

Type IV violation: $\frac{\Delta C}{\Delta S}>1, \Delta S \neq 0$; $\frac{\Delta P}{\Delta S}<-1, \Delta S \neq 0$.

Table 3 presents empirical results on testing the monotonicity property. It shows the occurrence rates of four different violations for the 30 expired warrants in Chinese warrant market. The results of S\&P 500 options by Bakshi, Cao and Chen (2000) are included as a benchmark in the last line of each table. From Table 3, we observe that the total occurrence rate of the four types of violations in the Chinese warrant market is higher than $50 \%$ for most of the warrants, sometimes even higher than $70 \%$, which is much higher than those in the U.S. market $(21.4 \%$ and 24.2\%). Through the trading in the past two and half years, the violation rates of call warrants are decreasing significantly. For example, the total frequency of violations of the call warrant, Zhonghua CWB1 (580011) traded on the Shanghai Stock Exchange, is 39.83\%. It expired on December 17, 2007. Another example is Shenfa SFC1 (031003), an expired (on December 28, 2007) call warrant traded on the Shenzhen Stock Exchange. Its total violation rate is 33.90\%. Compared with the warrants issued in 2005 or expired in 2006, whose total rates of violations are about $60 \%$ to $70 \%$, the violation rates of those newly-expired call warrants are decreasing significantly. However, the total violation rates of put warrants still remain at a level higher than $50 \%$, and there is no evidence to show that they are going to decrease.

Another interesting phenomenon is that, for call warrants, type IV violation is more likely to occur than type I violation, which means that call warrant prices are more likely to overreact to the price changes of their underlying stocks. Whereas for put warrants, type I violation happens much more frequently than type IV violation, which means put warrant prices are more likely to 
move in the wrong direction when the underlying stock prices changes. For type III violation, its occurrence rate in the U.S. is zero, whereas it is significantly above zero in the Chinese warrant market. We believe that it is caused by market microstructure, because the minimum tick size in the Chinese warrant market is 0.1 cent, but the minimum tick size in the stock market is 1 cent. Therefore it appears that warrant prices might change even though the underlying stock prices do not. We may conclude from Table 3 that the warrant prices in the Chinese warrant market do not support the monotonicity property of the one-dimensional diffusion models.

\subsection{Testing the perfect correlation property}

We compute the correlation matrix between the four assets: market warrant prices, Black-Scholes warrant prices, underlying stock prices and Shanghai Composite Index. We compute the correlation coefficients by using the time series of daily price changes of a warrant and its underlying asset. As a robustness test, we compute the correlation by using the Black-Scholes prices, which is supposed to be 1 for calls and -1 for puts.

Table 4 shows the correlation matrix of calls and puts separately. We see that the correlation between price changes of warrant and that of the underlying stock is not as high as 1 for calls and -1 for puts, different from the requirements of one-dimensional diffusion models. Especially for put warrants, the correlations are close to zero, which indicates that investors are trading put warrants as independent assets instead of derivatives of their underlying stocks. However, after two and half years of trading, the correlation between price changes of call warrants and those of underlying stocks increases significantly. For example, for Yager QCB1 (580006) traded on the Shanghai Stock Exchange, the correlation coefficient between price changes of the warrant and that of its underlying stock is 0.91. Another example is Qiaocheng HQC1 (031001) traded on the Shenzhen Stock Exchange. The correlation coefficient between price changes of the warrant and that of its underlying stock is 0.91 . However, there is no evidence that the correlation coefficients of the put warrants approach -1 . Our result on the correlation between price changes from the Black-Scholes formula and that of the underlying stocks is almost 1 for most of the calls. This 
indicates that our calculation is reliable. These results mean that the put warrants prices in the Chinese warrant market do not support the perfect correlation property of one-dimensional diffusion models. Their correlations with the underlying stocks are almost zero. Investors are trading put warrants as independent assets instead of derivatives of their underlying stocks.

\subsection{Testing the option redundancy property}

The cumulated delta-hedged gains defined in equation (4) can be written in a discrete form as follows

$$
\pi(t, t+\tau)=C_{t+\tau}-C_{t}-\sum_{n=0}^{N-1} \Delta_{t_{n}}\left(S_{t_{n+1}}-S_{t_{n}}\right)-\sum_{n=0}^{N-1} r\left(C_{t_{n}}-\Delta_{t_{n}} S_{t_{n}}\right) \frac{\tau}{N}
$$

where $t_{0}=t, t_{N}=t+\tau$ is the maturity date, and $\Delta_{t_{n}}$ is the hedge ratio at $t_{n}$. The hedge is rebalanced daily ( $\tau / N=1 / 242$, where 242 is trading days in one year in the Chinese financial market), and the option delta is computed as the Black-Scholes hedge ratio, $\Delta_{t_{n}}=N\left(d_{1}\left(S_{t_{n}}, t_{n}\right)\right)$, where $N(\cdot)$ is the cumulative normal distribution function, and $d_{1}\left(S_{t_{n}}, t_{n}\right)=\frac{\ln \left(S_{t_{n}} / K\right)+\left(r_{t_{n}}+\frac{1}{2} \sigma_{t_{n}}{ }^{2}\right) \tau_{n}}{\sigma_{t_{n}} \sqrt{\tau_{n}}}$, with $\sigma_{t_{n}}$ is historical volatility ${ }^{2}$. We calculate the cumulated delta-hedged gains $\pi(t, t+\tau)$ for each warrant over its life time; the delta-hedged gains normalized by the initial price of the underlying stock $\left(\pi(t, t+\tau) / S_{t}\right.$, in \%), and the initial warrant price $\left(\pi(t, t+\tau) / C_{t}\right.$, in \%); and then the occurrence frequency of $d \pi<0$ (in \%) in the time series of each delta-hedged portfolio. A warrant is not a redundant asset if the cumulated gain is significantly nonzero.

Table 5 reports the sign and the magnitude of cumulated delta-hedged gains for all the 30 expired warrants. Column four of the table shows the cash amount of the gains, $\pi(t, t+\tau)$. Columns five and six present the relative amount of the gains, normalized by the initial

\footnotetext{
2 Bates' (2005) method (to compute a model-free delta by using option prices with different strikes) cannot be applied in the Chinese warrant market, since at a certain time we only have one or two strikes for warrants on an underlying stock.
} 
underlying stock price $S_{t}$ and warrant price $C_{t}$, in order to make the cumulated delta-hedged gains comparable across the time-series and the cross-section. The last column reports the occurrence frequency of negative delta-hedged gains over the lifetime of the warrants.

According to Table 5, the delta-hedging strategies lose money for 90\% (27 out of 30) of the warrants with an average loss of CNY -1.09. “The money left on the table” equals $14.11 \%$ of the underlying asset value on average, or $46.48 \%$ of the warrant price itself. In the U.S. market, for all firms, on average, the delta-hedging strategy loses $0.03 \%$ of the underlying asset value, and the same delta-hedging strategy for the index option has a loss of $0.07 \%$ of the underlying index level (Bakshi and Kapadia (2003b)). For call warrants, the delta-hedging strategy loses $16.75 \%$ of the underlying asset value, or $45.70 \%$ of the warrant value. For put warrants, the strategy loses $11.79 \%$ of the underlying asset value, or $47.17 \%$ of the warrant value. The occurrence frequency of negative delta-hedged gains is higher than $50 \%$ for both call and put warrants. Our results remain robust when the median is taken as the measure of central tendency. The amount of negative delta-hedged gains in the Chinese warrant market is much larger than that in the U.S. market, because only a small portion of institutions (innovation pilot securities dealers) could take short position of warrants in China. They can take "the money left on the table" away by constructing the opposite position as the delta-hedging strategy. Since the cumulated delta-hedged gain is significantly nonzero, we may conclude that the warrants are not redundant assets in the Chinese warrant market. We explore the additional risk factors traded in the warrant market in the following.

4.4 The additional risk factors traded in the warrant market: what drives the delta-hedged gains?

We try to identify the sources of the delta-hedged gains by using OLS regressions on the time series of the gains against the 11 possible explanatory variables. The explanatory variables include: index return, index volatility, index trading volume, underlying stock return, underlying stock volatility with the two measures, underlying stock trading volume and trading value, 
warrant trading volume and trading value. In particular, the daily volatility is calculated by using the Parkinson (1980) measure

$$
\hat{\sigma}_{P}=\sqrt{\frac{1}{4 \ln 2}\left(\ln \frac{H_{t}}{L_{t}}\right)^{2}},
$$

and the Rogers and Satchell (1991) measure

$$
\hat{\sigma}_{R S}=\sqrt{\ln \frac{H_{t}}{O_{t}} \ln \frac{H_{t}}{C_{t}}+\ln \frac{L_{t}}{O_{t}} \ln \frac{L_{t}}{C_{t}}},
$$

where $O_{t}, H_{t}, L_{t}$ and $C_{t}$ stand for the daily open, high, low and close prices respectively.

We find that not all of the 11 variables are significant, and decide to report results on four variables, that could answer our main concerns. These four variables are: (1) market index return, (2) market index daily volatility, (3) underlying stock daily volatility, and (4) warrant trading value. Regarding the two different measures of daily volatility, we find that the regression results with the two measures are similar to each other. We decide to report the result with only one of them, the Parkinson (1980) estimator. In order to obtain an intuitive relation between delta-hedged gains and the explanatory variables, we run the following panel data regressions by pooling the data of all 14 call warrants or 16 put warrants:

$$
\begin{aligned}
& \text { GAINS }=\alpha+\beta_{1} \text { IdxRt }+\varepsilon_{1}, \\
& \text { GAINS }=\alpha+\beta_{2} \text { IdxVol }+\varepsilon_{2}, \\
& \text { GAINS }=\alpha+\beta_{3} \text { SVol }+\varepsilon_{3}, \\
& \text { GAINS }=\alpha+\beta_{4} \text { TrdValue }+\varepsilon_{4}, \\
& \text { GAINS }=\alpha+\beta_{1} \text { IdxRt }+\beta_{2} \text { IdxVol }+\beta_{3} \text { SVol }+\beta_{4} \text { TrdValue }+\varepsilon_{1234},
\end{aligned}
$$

where GAINS is the daily gains of delta-hedged warrants; IdxRt is market index return; IdxVol is daily market index volatility; SVol is daily underlying stock volatility; TrdValue is warrant trading value.

Table 6 provides the results of the panel regressions. We observe that the coefficients of IdxVol and SVol are significant at 5\% level both for calls and puts, which means that the volatility 
risk is one of the main sources in the delta-hedged gains. The coefficients of market risk (IdxRt) are significant at 5\% level for calls and the coefficients of TrdValue are significant at $10 \%$ level for puts, which means that investors are also trading some other risks in the Chinese warrant market in addition to the underlying risks.

Recently, Bakshi, Madan and Panayotov (2010) propose a theory of U-shaped pricing kernel for equity. Based on this theory, they have a testable implication for call options: higher the strike, lower the return of out-of-the-money (OTM) calls. The return of OTM calls could be negative if strike is higher than a certain threshold. The empirical observations from S\&P 500 index options and international equity options markets support their theory. Because in Chinese warrant market, we only have one strike and one maturity (usually one year), it is not possible to perform a similar test.

\section{Conclusions}

In this paper, we study the newly-developed Chinese warrant market by using the data of all the 30 expired warrants (14 calls and 16 puts) between August 22, 2005 and March 14, 2008. Our research focuses on the applicability of one-dimensional diffusion models in this new emerging derivative market, and the additional risk factors traded in this market. We have the following observations:

The warrants are much over-priced compared with the Black-Scholes prices with historical volatility, sometimes more than twice. The implied volatility of the warrants is very high, sometimes $100 \%$ for calls, and even $1000 \%$ for puts, especially for those short-term deeply out-of-the-money put warrants.

Arbitrage can be achieved if investors are allowed to sell the warrants to the market. In fact, some institutions (innovation pilot securities dealers), with permissions from the regulators to create warrants, are making huge arbitrage profit by creating and selling warrants. Investors lack the basic knowledge of warrants, such as their intrinsic value, the zero value of deeply 
out-of-the-money put.

One-dimensional diffusion models, including the Black-Scholes model, do not apply in the Chinese warrant market. The investors are trading some other risk factors in the Chinese warrant market, in addition to the underlying risk.

The cumulated delta-hedged gains in the Chinese warrant market are significantly negative. The negative gains are mainly driven by volatility risk, and the trading value of the warrants (for puts), and the market risk (for calls). 


\section{References}

Bakshi, Gurdip, Charles Cao, and Zhiwu Chen, 2000, Do call prices and the underlying stock always move in the same direction? Review of Financial Studies 13, 549-584.

Bakshi, Gurdip, and Nikunj Kapadia, 2003a, Delta-hedged gains and the negative market volatility risk premium, Review of Financial Studies 16 (2), 527-566.

Bakshi, Gurdip, and Nikunj Kapadia, 2003b, Volatility risk premium embedded in individual equity options: some new insights, Journal of Derivatives (Fall issue), 45-54.

Bakshi, Gurdip, Dilip Madan, and George Panayotov, 2010, Returns of claims on the upside and the viability of U-shaped pricing kernels, Journal of Financial Economics 97, 130-154.

Bates, David S., 2005, Hedging the smirk, Finance Research Letters 2, 195-200.

Bergman, Yaacov Z., Bruce D. Grundy, and Zvi Wiener, 1996, General properties of option prices, Journal of Finance 51, 1573-1610.

Black, Fischer, and Myron S. Scholes, 1973, The pricing of options and corporate liabilities, Journal of Political Economy 81, 637-659.

Cox, John, and Stephen Ross, 1976, The valuation of options for alternative stochastic processes, Journal of Financial Economics 3, 145-166.

Derman, Emanuel, and Iraj Kani, 1994a, The volatility smile and its implied tree, Quantitative Strategies Research Notes (Goldman Sachs, New York).

Derman, Emanuel, and Iraj Kani, 1994b, Riding on the smile, Risk 7, 32-39.

Dupire, Bruno, 1994, Pricing with a smile, Risk 7, 18-20.

Harrison, J. M., and D. M. Kreps, 1978, Speculative investor behavior in a stock-market with heterogeneous expectations, Quarterly Journal of Economics 92, 323-336.

Heston, Steven L., 1993, A closed-form solution for options with stochastic volatility with applications to bond and currency options, Review of Financial Studies 6, 327-343.

Merton, Robert, 1973, Theory of rational option pricing, Bell Journal of Economics 4, 141-183.

Newey, W., and K. West, 1987, A simple, positive semi-definite, heteroskedasticity and autocorrelation consistent covariance matrix, Econometrica 55, 703-708.

Parkinson, Michael, 1980, The extreme value method for estimating the variance of the rate of return, Journal of Business 53, 61-68.

Powers, Eric, Gang Xiao, and Hong Yan, 2009, Convenience yield and the Chinese warrants, Working paper, University of South Carolina.

Rogers, L. C. G., and Satchell, S. E, 1991, Estimating variance from high, low and closing prices, Annals of Applied Probability 1, 504-512.

Rubinstein, Mark, 1994, Implied binomial trees, Journal of Finance 49, 771-818.

Wu, Tao L., 2011, A comprehensive study of the Chinese warrants bubble, Working paper, Illinois Institute of Technology.

Xiong, Wei, and Jialin Yu, 2011, The Chinese warrants bubble, American Economic Review 101, 2723-2753. 
Table 1: The detailed differences between equity warrants and covered warrants

\begin{tabular}{|c|c|c|}
\hline & Equity warrants & Covered warrants \\
\hline Issuer & $\begin{array}{l}\text { Listed company } \\
\text { (the issuer of the underlying assets) }\end{array}$ & $\begin{array}{l}\text { independent third party } \\
\text { (usually financial institutions such as investment banks) }\end{array}$ \\
\hline $\begin{array}{l}\text { Purpose of } \\
\text { issuance }\end{array}$ & Financing for listed companies & $\begin{array}{l}\text { To provide risk management and investment instruments for } \\
\text { customers }\end{array}$ \\
\hline $\begin{array}{l}\text { The result of } \\
\text { exercise }\end{array}$ & $\begin{array}{l}\text { When equity warrants are exercised, the listed company } \\
\text { must issue new shares and sell them at strike price to } \\
\text { the warrants holder (take call warrants as an example). } \\
\text { The total number of outstanding shares is increased } \\
\text { after exercise of the warrants. } \\
\text { There is a dilution effect. }\end{array}$ & $\begin{array}{l}\text { When covered warrants are exercised, if it is stock } \\
\text { settlement, the warrants issuer just sell stocks to } \\
\text { warrants holder, if it is cash settlement, the warrants issuer } \\
\text { just pay the difference between strike price and the } \\
\text { underlying asset price in cash to the warrants holder. } \\
\text { The number of outstanding shares will not be changed. } \\
\text { There is no dilution effect. }\end{array}$ \\
\hline Underlying assets & Single stock & Single stock, or portfolio of stocks, or index \\
\hline Time to expiration & usually 1 to 5 years & usually 6 months to 2 years \\
\hline Settlement & deliver stocks & deliver stocks, or settled by cash \\
\hline
\end{tabular}


Table 2: Summary statistics of warrants and their underlying stocks. This table shows, for each of the 30 expired warrants, the average daily trading volume, the average daily Yuan volume (trading value), daily average market price (close price) and daily average Black-Scholes price, daily average time value computed from the market price and Black-Scholes price, daily average implied volatility and historical volatility. The t-statistics are in square brackets. Statistical significance at the $1 \%, 5 \%$ and $10 \%$ levels are denoted by $* * *$, ** and *, respectively.

\section{Call warrants:}

\begin{tabular}{|c|c|c|c|c|c|c|c|c|c|c|c|c|c|}
\hline \multirow[b]{2}{*}{$\begin{array}{c}\text { Warrant } \\
\text { code }\end{array}$} & \multirow[b]{2}{*}{ Warrant Name } & \multicolumn{4}{|c|}{ Avg daily trading volume (in million) } & \multicolumn{4}{|c|}{ Avg daily Yuan volume (trading value) (in million) } & \multicolumn{4}{|c|}{ Avg daily close price of warrant } \\
\hline & & warrant & $\begin{array}{l}\text { underlying } \\
\text { stock }\end{array}$ & Avg Diff & t of Diff & warrant & $\begin{array}{l}\text { underlying } \\
\text { stock }\end{array}$ & Avg Diff & t of Diff & market price & $\begin{array}{c}\text { Black-Scholes } \\
\text { price }\end{array}$ & Avg Diff & t of Diff \\
\hline 580000 & Baosteel JTB1 & 575 & 46 & $529 * * *$ & [13.65] & 736 & 197 & $538 * * *$ & [10.75] & 1.30 & 0.24 & $1.06 * * *$ & [43.85] \\
\hline 580001 & Wuhan steel JTB1 & 1060 & 43 & $1017 * * *$ & [18.58] & 945 & 124 & $821 * * *$ & [13.93] & 0.81 & 0.35 & $0.46 * * *$ & [39.28] \\
\hline 580002 & BaoSteel JTB1 & 771 & 76 & $695 * * *$ & [25.10] & 1,139 & 244 & $895 * * *$ & [17.21] & 1.39 & 1.13 & $0.25 * * *$ & [17.54] \\
\hline 580003 & HanSteel JTB1 & 653 & 29 & $623 * * *$ & [24.74] & 1,307 & 134 & $1173 * * *$ & [19.19] & 1.90 & 1.60 & $0.30 * * *$ & [18.40] \\
\hline 580004 & Shouchuang JTB1 & 181 & 21 & $160 * * *$ & [22.68] & 532 & 130 & $402 * * *$ & [17.59] & 2.82 & 1.68 & $1.14 * * *$ & [47.59] \\
\hline 580005 & Wanhua HXB1 & 7 & 5 & $2 * * *$ & [3.57] & 106 & 113 & -7 & {$[-0.96]$} & 19.32 & 20.58 & $-1.26 * * *$ & {$[-8.37]$} \\
\hline 580006 & Yager QCB1 & 70 & 25 & $46 * * *$ & [14.81] & 418 & 285 & $134 * * *$ & [7.23] & 6.34 & 5.62 & $0.72 * * *$ & [21.84] \\
\hline 580007 & Changdian CWB1 & 120 & 53 & $67 * * *$ & [13.85] & 644 & 532 & $112 * * *$ & [4.32] & 4.56 & 3.61 & $0.95 * * *$ & [19.20] \\
\hline 580008 & Guodian JTB1 & 151 & 37 & $114 * * *$ & [19.56] & 1,011 & 418 & $592 * * *$ & [12.90] & 6.39 & 5.59 & $0.80 * * *$ & [21.40] \\
\hline 580009 & Yili CWB1 & 30 & 11 & $18 * * *$ & [13.33] & 698 & 343 & $355 * * *$ & [9.49] & 21.35 & 21.58 & $-0.23 * * *$ & {$[-3.47]$} \\
\hline 580011 & Zhonghua CWB1 & 137 & 22 & $115^{* * *}$ & [24.50] & 1,553 & 358 & $1195 * * *$ & [17.06] & 10.90 & 10.08 & $0.83 * * *$ & [8.45] \\
\hline 030001 & Ansteel JTC1 & 77 & 21 & $55 * * *$ & [16.10] & 235 & 123 & $112 * * *$ & [10.99] & 3.02 & 2.17 & $0.85 * * *$ & [25.24] \\
\hline 031001 & Qiaocheng HQC1 & 30 & 9 & $21 * * *$ & [18.66] & 768 & 267 & $502 * * *$ & [13.71] & 28.23 & 30.59 & $-2.36 * * *$ & {$[-14.59]$} \\
\hline \multirow[t]{3}{*}{031003} & Shenfa SFC1 & 53 & 24 & $30 * * *$ & {$[7.05]$} & 1,036 & 875 & $161 * *$ & [2.10] & 19.68 & 18.50 & $1.18 * * *$ & {$[5.66]$} \\
\hline & Average & 280 & 30 & 250 & & 795 & 296 & 499 & & 9.14 & 8.81 & 0.33 & \\
\hline & p-value & 0.01 & 0.00 & 0.01 & & 0.00 & 0.00 & 0.00 & & 0.00 & 0.00 & 0.24 & \\
\hline
\end{tabular}




\begin{tabular}{|c|c|c|c|c|c|c|c|c|c|}
\hline \multirow[b]{2}{*}{$\begin{array}{c}\text { Warrant } \\
\text { code }\end{array}$} & \multirow[b]{2}{*}{ Warrant Name } & \multicolumn{4}{|c|}{ Avg time value of warrant } & \multicolumn{4}{|c|}{ Avg volatility } \\
\hline & & $\begin{array}{c}\text { from market } \\
\text { price }\end{array}$ & from BS price & Avg Diff & t of Diff & implied volatility & historical volatility & Avg Diff & t of Diff \\
\hline 580000 & Baosteel JTB1 & 1.26 & 0.21 & $1.06 * * *$ & [43.85] & 1.35 & 0.26 & $1.09 * * *$ & {$[44.30]$} \\
\hline 580001 & Wuhan steel JTB1 & 0.73 & 0.27 & $0.46 * * *$ & [39.28] & 1.23 & 0.43 & $0.80 * * *$ & {$[26.35]$} \\
\hline 580002 & BaoSteel JTB1 & 0.52 & 0.27 & $0.25 * * *$ & [17.54] & 1.53 & 0.72 & $0.79 * * *$ & {$[19.05]$} \\
\hline 580003 & HanSteel JTB1 & 0.44 & 0.14 & $0.30 * * *$ & [18.40] & 1.20 & 0.50 & $0.71 * * *$ & {$[19.49]$} \\
\hline 580004 & Shouchuang JTB1 & 1.53 & 0.39 & $1.14 * * *$ & [47.59] & 1.91 & 0.51 & $1.40 * * *$ & {$[24.38]$} \\
\hline 580005 & Wanhua HXB1 & -1.20 & 0.06 & $-1.26 * * *$ & {$[-8.37]$} & 3.72 & 0.57 & $3.14 * * *$ & {$[19.48]$} \\
\hline 580006 & Yager QCB1 & 0.83 & 0.11 & $0.72 * * *$ & [21.84] & 1.84 & 0.56 & $1.27 * * *$ & {$[22.49]$} \\
\hline 580007 & Changdian CWB1 & 1.00 & 0.05 & $0.95 * * *$ & [19.20] & 1.24 & 0.28 & $0.97 * * *$ & {$[41.11]$} \\
\hline 580008 & Guodian JTB1 & 0.99 & 0.19 & $0.80 * * *$ & [21.40] & 1.73 & 0.52 & $1.20 * * *$ & {$[19.17]$} \\
\hline 580009 & Yili CWB1 & -0.23 & 0.00 & $-0.23 * * *$ & {$[-3.47]$} & 1.81 & 0.46 & $1.36 * * *$ & {$[17.02]$} \\
\hline 580011 & Zhonghua CWB1 & 0.96 & 0.13 & $0.83 * * *$ & [8.45] & 1.66 & 0.56 & $1.13 * * *$ & {$[31.14]$} \\
\hline 030001 & Ansteel JTC1 & 0.91 & 0.07 & $0.85 * * *$ & [25.24] & 1.66 & 0.38 & $1.28 * * *$ & {$[37.76]$} \\
\hline 031001 & Qiaocheng HQC1 & -2.35 & 0.01 & $-2.36 * * *$ & [-14.59] & 1.10 & 0.57 & $0.55 * * *$ & {$[32.08]$} \\
\hline \multirow[t]{3}{*}{031003} & Shenfa SFC1 & 1.26 & 0.09 & $1.18 * * *$ & [5.66] & 1.44 & 0.50 & $0.92 * * *$ & {$[16.70]$} \\
\hline & Average & 0.48 & 0.14 & 0.33 & & 1.67 & 0.49 & 1.18 & \\
\hline & p-value & 0.12 & 0.00 & 0.24 & & 0.00 & 0.00 & 0.00 & \\
\hline
\end{tabular}


Put warrants:

\begin{tabular}{|c|c|c|c|c|c|c|c|c|c|c|c|c|c|}
\hline \multirow[b]{2}{*}{$\begin{array}{c}\text { Warrant } \\
\text { code }\end{array}$} & \multirow[b]{2}{*}{ Warrant Name } & \multicolumn{4}{|c|}{ Avg daily trading volume (in million) } & \multicolumn{4}{|c|}{ Avg daily Yuan volume (trading value) (in million) } & \multicolumn{4}{|c|}{ Avg daily close price of warrant } \\
\hline & & warrant & $\begin{array}{l}\text { underlying } \\
\text { stock }\end{array}$ & Avg Diff & t of Diff & warrant & $\begin{array}{l}\text { underlying } \\
\text { stock }\end{array}$ & Avg Diff & t of Diff & market price & $\begin{array}{c}\text { Black-Scholes } \\
\text { price }\end{array}$ & Avg Diff & $t$ of Diff \\
\hline 580990 & Maotai JCP1 & 463 & 3 & $460 * * *$ & {$[8.36]$} & 382 & 229 & $153 * * *$ & [5.32] & 1.03 & 0.66 & $0.37 * * *$ & [11.57] \\
\hline 580991 & Haier JTP1 & 473 & 16 & $457 * * *$ & {$[9.75]$} & 306 & 145 & $161 * * *$ & [7.92] & 0.72 & 0.12 & $0.61 * * *$ & [49.99] \\
\hline 580992 & Yager QCP1 & 550 & 25 & $525 * * *$ & [10.71] & 354 & 285 & $69 * *$ & [2.09] & 0.68 & 0.18 & $0.50 * * *$ & [34.32] \\
\hline 580993 & Wanhua HXP1 & 167 & 5 & $162 * * *$ & [9.39] & 221 & 113 & $108 * * *$ & [7.43] & 1.48 & 0.37 & $1.12 * * *$ & [26.92] \\
\hline 580994 & Yuanshui CTP1 & 383 & 14 & $368 * * *$ & [9.59] & 362 & 80 & $282 * * *$ & [10.56] & 0.99 & 0.40 & $0.59 * * *$ & [28.93] \\
\hline 580995 & Baosteel JTP1 & 879 & 76 & $803 * * *$ & [11.35] & 485 & 244 & $240 * * *$ & [7.92] & 0.56 & 0.45 & $0.11 * * *$ & [5.25] \\
\hline 580996 & Huchang JTP1 & 483 & 13 & $471 * * *$ & [10.54] & 453 & 197 & $255 * * *$ & [9.68] & 1.16 & 1.26 & $-0.09 * *$ & {$[-2.03]$} \\
\hline 580997 & Zhaohang CMP1 & 4,216 & 79 & 4137 *** & [8.64] & 3,171 & 1,184 & $1987 * * *$ & [4.98] & 0.51 & 0.18 & $0.33 * * *$ & [12.94] \\
\hline 580998 & Jichang JTP1 & 297 & 8 & $290 * * *$ & [16.27] & 339 & 51 & $288 * * *$ & [16.02] & 1.18 & 0.67 & $0.50 * * *$ & [27.23] \\
\hline 580999 & Wuhan steel JTP1 & 595 & 43 & $552 * * *$ & [9.635] & 371 & 124 & $247 * * *$ & [8.74] & 0.69 & 0.45 & $0.24 * * *$ & [23.51] \\
\hline 038001 & Gangfan PGP1 & 185 & 35 & $149 * * *$ & [11.65] & 215 & 178 & $37 * * *$ & [2.85] & 1.23 & 0.84 & $0.39 * * *$ & [16.06] \\
\hline 038002 & Wanke HRP1 & 1,403 & 50 & $1354 * * *$ & [12.37] & 503 & 285 & $219 * * *$ & [5.02] & 0.43 & 0.15 & $0.29 * * *$ & [26.24] \\
\hline 038003 & Hualing JTP1 & 672 & 34 & $638 * * *$ & [15.03] & 1,407 & 270 & $1137 * * *$ & [9.90] & 1.67 & 0.60 & $1.07 * * *$ & [16.89] \\
\hline 038005 & Shenneng JTP1 & 590 & 10 & $579 * * *$ & [10.71] & 396 & 75 & $320 * * *$ & [10.16] & 0.81 & 0.43 & $0.38 * * *$ & [15.88] \\
\hline 038006 & Zhongji ZYP1 & 560 & 20 & $540 * * *$ & [12.51] & 1,424 & 469 & $955 * * *$ & [6.63] & 1.76 & 0.57 & $1.19 * * *$ & [12.83] \\
\hline \multirow[t]{3}{*}{038008} & Jiafei JTP1 & 161 & 5 & $156 * * *$ & [8.48] & 425 & 145 & $280 * * *$ & [3.79] & 1.67 & 0.30 & $1.37 * * *$ & [25.98] \\
\hline & Average & 755 & 27 & 728 & & 676 & 255 & 421 & & 1.04 & 0.48 & 0.56 & \\
\hline & p-value & 0.01 & 0.00 & 0.01 & & 0.00 & 0.00 & 0.00 & & 0.00 & 0.00 & 0.00 & \\
\hline
\end{tabular}




\begin{tabular}{|c|c|c|c|c|c|c|c|c|c|}
\hline \multirow[b]{2}{*}{ Warrant code } & \multirow[b]{2}{*}{ Warrant Name } & \multicolumn{4}{|c|}{ Avg time value of warrant } & \multicolumn{4}{|c|}{ Avg volatility } \\
\hline & & $\begin{array}{c}\text { from market } \\
\text { price }\end{array}$ & from BS price & Avg Diff & t of Diff & implied volatility & historical volatility & Avg Diff & t of Diff \\
\hline 580990 & Maotai JCP1 & 1.03 & 0.66 & $0.37 * * *$ & [11.57] & 1.09 & 0.80 & $0.29 * * *$ & {$[4.01]$} \\
\hline 580991 & Haier JTP1 & 0.72 & 0.12 & $0.61 * * *$ & [49.99] & 1.55 & 0.31 & $1.24 * * *$ & {$[13.78]$} \\
\hline 580992 & Yager QCP1 & 0.68 & 0.18 & $0.50 * * *$ & [34.32] & 1.79 & 0.56 & $1.23 * * *$ & {$[11.66]$} \\
\hline 580993 & Wanhua HXP1 & 1.48 & 0.37 & $1.12 * * *$ & [26.92] & 1.92 & 0.57 & $1.36 * * *$ & {$[10.76]$} \\
\hline 580994 & Yuanshui CTP1 & 0.97 & 0.38 & $0.59 * * *$ & [28.93] & 1.19 & 0.42 & $0.76 * * *$ & {$[14.01]$} \\
\hline 580995 & Baosteel JTP1 & 0.48 & 0.37 & $0.11 * * *$ & {$[5.25]$} & 1.59 & 0.72 & $0.86 * * *$ & {$[6.06]$} \\
\hline 580996 & Huchang JTP1 & 0.88 & 0.97 & $-0.09 * *$ & {$[-2.03]$} & 0.70 & 0.40 & $0.30 * * *$ & {$[4.86]$} \\
\hline 580997 & Zhaohang CMP1 & 0.51 & 0.18 & $0.33 * * *$ & [12.94] & 1.57 & 0.40 & $1.17 * * *$ & {$[10.85]$} \\
\hline 580998 & Jichang JTP1 & 0.89 & 0.39 & $0.50 * * *$ & [27.23] & 0.75 & 0.29 & $0.46 * * *$ & {$[9.53]$} \\
\hline 580999 & Wuhan steel JTP1 & 0.47 & 0.23 & $0.24 * * *$ & [23.51] & 0.86 & 0.43 & $0.43 * * *$ & {$[14.23]$} \\
\hline 038001 & Gangfan PGP1 & 0.99 & 0.61 & $0.39 * * *$ & {$[16.06]$} & 1.83 & 0.69 & $1.16 * * *$ & {$[11.04]$} \\
\hline 038002 & Wanke HRP1 & 0.43 & 0.15 & $0.29 * * *$ & [26.24] & 1.19 & 0.49 & $0.71 * * *$ & [18.68] \\
\hline 038003 & Hualing JTP1 & 1.27 & 0.20 & $1.07 * * *$ & [16.89] & 1.70 & 0.40 & $1.30 * * *$ & {$[16.53]$} \\
\hline 038005 & Shenneng JTP1 & 0.80 & 0.40 & $0.38 * * *$ & [15.88] & 0.75 & 0.41 & $0.34 * * *$ & {$[18.79]$} \\
\hline 038006 & Zhongji ZYP1 & 1.76 & 0.57 & $1.19 * * *$ & [12.83] & 2.11 & 0.54 & $1.57 * * *$ & {$[14.32]$} \\
\hline \multirow[t]{3}{*}{038008} & Jiafei JTP1 & 1.67 & 0.30 & $1.37 * * *$ & [25.98] & 1.60 & 0.39 & $1.21 * * *$ & {$[8.12]$} \\
\hline & Average & 0.94 & 0.38 & 0.56 & & 1.39 & 0.49 & 0.90 & \\
\hline & p-value & 0.00 & 0.00 & 0.00 & & 0.00 & 0.00 & 0.00 & \\
\hline
\end{tabular}


Table 3: Empirical results from testing the monotonicity property of the $\mathbf{3 0}$ expired warrants. The last lines of the two tables for call and put warrants are the results of S\&P 500 options, adopted from Bakshi, Cao, and Chen (2000).

Call warrants:

\begin{tabular}{|c|c|c|c|c|c|c|c|c|c|}
\hline \multicolumn{2}{|c|}{ Violation } & \multirow{2}{*}{$\begin{array}{c}\text { Type I } \\
\Delta \mathrm{C}^{*} \Delta \mathrm{S}<0\end{array}$} & \multirow{2}{*}{$\frac{\text { Type IV }}{\Delta \mathrm{C} / \Delta \mathrm{S}>1}$} & \multirow{2}{*}{$\begin{array}{c}\text { Type II } \\
\Delta \mathrm{S}<>0, \Delta \mathrm{C}=0\end{array}$} & \multirow{2}{*}{$\begin{array}{c}\text { Type III } \\
\Delta \mathrm{S}=0, \Delta \mathrm{C}<>0\end{array}$} & \multicolumn{2}{|c|}{ Sub-categories of Type I } & \multirow{2}{*}{$\begin{array}{c}\text { Type I and } \\
\text { Type IV total }\end{array}$} & \multirow{2}{*}{ Total } \\
\hline Wrt Code & Wrt Name & & & & & $\Delta \mathrm{S}<0, \Delta \mathrm{C}>0$ & $\Delta \mathrm{S}>0, \Delta \mathrm{C}<0$ & & \\
\hline 580000 & Baosteel JTB1 & $33.47 \%$ & $30.58 \%$ & $4.55 \%$ & $7.02 \%$ & $14.05 \%$ & $19.42 \%$ & $64.05 \%$ & $75.62 \%$ \\
\hline 580001 & Wuhan steel JTB1 & $30.77 \%$ & $30.34 \%$ & $0.85 \%$ & $8.97 \%$ & $12.82 \%$ & $17.95 \%$ & $61.11 \%$ & $70.94 \%$ \\
\hline 580002 & BaoSteel JTB1 & $18.97 \%$ & $38.36 \%$ & $0.43 \%$ & $6.47 \%$ & $8.62 \%$ & $10.34 \%$ & $57.33 \%$ & $64.22 \%$ \\
\hline 580003 & HanSteel JTB1 & $21.46 \%$ & $35.62 \%$ & $0.43 \%$ & $4.72 \%$ & $9.87 \%$ & $11.59 \%$ & $57.08 \%$ & $62.23 \%$ \\
\hline 580004 & Shouchuang JTB1 & $18.45 \%$ & $36.48 \%$ & $0.86 \%$ & $4.29 \%$ & $6.44 \%$ & $12.02 \%$ & $54.94 \%$ & $60.09 \%$ \\
\hline 580005 & Wanhua HXB1 & $16.17 \%$ & $43.40 \%$ & $0.43 \%$ & $0.85 \%$ & $9.79 \%$ & $6.38 \%$ & $59.57 \%$ & $60.85 \%$ \\
\hline 580006 & Yager QCB1 & $13.14 \%$ & $38.14 \%$ & $0.00 \%$ & $0.85 \%$ & $6.36 \%$ & $6.78 \%$ & $51.27 \%$ & $52.12 \%$ \\
\hline 580007 & Changdian CWB1 & $21.37 \%$ & $26.50 \%$ & $0.00 \%$ & $3.85 \%$ & $10.68 \%$ & $10.68 \%$ & $47.86 \%$ & $51.71 \%$ \\
\hline 580008 & Guodian JTB1 & $17.03 \%$ & $33.62 \%$ & $0.87 \%$ & $1.75 \%$ & $7.42 \%$ & $9.61 \%$ & $50.66 \%$ & $53.28 \%$ \\
\hline 580009 & Yili CWB1 & $11.91 \%$ & $32.34 \%$ & $0.43 \%$ & $0.85 \%$ & $5.96 \%$ & $5.96 \%$ & $44.26 \%$ & $45.53 \%$ \\
\hline 580011 & Zhonghua CWB1 & $11.26 \%$ & $26.41 \%$ & $0.00 \%$ & $2.16 \%$ & $3.46 \%$ & $7.79 \%$ & $37.66 \%$ & $39.83 \%$ \\
\hline 030001 & Ansteel JTC1 & $20.94 \%$ & $35.47 \%$ & $0.00 \%$ & $4.71 \%$ & $8.55 \%$ & $12.39 \%$ & $56.41 \%$ & $61.11 \%$ \\
\hline 031001 & Qiaocheng HQC1 & $13.24 \%$ & $25.11 \%$ & $0.00 \%$ & $2.74 \%$ & $8.22 \%$ & $5.02 \%$ & $38.36 \%$ & $41.10 \%$ \\
\hline 031003 & Shenfa SFC1 & $16.95 \%$ & $15.25 \%$ & $0.85 \%$ & $0.85 \%$ & $8.47 \%$ & $8.47 \%$ & $32.20 \%$ & $33.90 \%$ \\
\hline \multicolumn{2}{|r|}{ Average } & $18.94 \%$ & $31.97 \%$ & $0.69 \%$ & $3.58 \%$ & $8.62 \%$ & $10.32 \%$ & $50.91 \%$ & $55.18 \%$ \\
\hline \multicolumn{2}{|c|}{ S\&P 500 Calls } & $9.10 \%$ & $11.50 \%$ & $3.60 \%$ & $0.00 \%$ & - & - & $20.60 \%$ & $24.20 \%$ \\
\hline
\end{tabular}


Put warrants:

\begin{tabular}{|c|c|c|c|c|c|c|c|c|c|}
\hline \multicolumn{2}{|c|}{ Violation } & \multirow{2}{*}{$\frac{\text { Type I }}{\Delta \mathrm{P}^{*} \Delta \mathrm{S}>0}$} & \multirow{2}{*}{$\frac{\text { Type IV }}{\Delta \mathrm{P} / \Delta \mathrm{S}<-1}$} & \multirow{2}{*}{$\begin{array}{c}\text { Type II } \\
\Delta \mathrm{S}<>0, \Delta \mathrm{P}=0\end{array}$} & \multirow{2}{*}{$\begin{array}{c}\text { Type III } \\
\Delta \mathrm{S}=0, \Delta \mathrm{P}<>0\end{array}$} & \multicolumn{2}{|c|}{ Sub-categories of Type I } & \multirow{2}{*}{$\begin{array}{c}\text { Type I and } \\
\text { Type IV total }\end{array}$} & \multirow{2}{*}{ Total } \\
\hline Wrt Code & Wrt Name & & & & & $\Delta \mathrm{S}>0, \Delta \mathrm{P}>0$ & $\Delta \mathrm{S}<0, \Delta \mathrm{P}<0$ & & \\
\hline 580990 & Maotai JCP1 & $49.79 \%$ & $0.86 \%$ & $1.72 \%$ & $0.86 \%$ & $24.03 \%$ & $25.75 \%$ & $50.64 \%$ & $53.22 \%$ \\
\hline 580991 & Haier JTP1 & $48.26 \%$ & $7.39 \%$ & $1.30 \%$ & $3.91 \%$ & $26.52 \%$ & $21.74 \%$ & $55.65 \%$ & $60.87 \%$ \\
\hline 580992 & Yager QCP1 & $46.61 \%$ & $5.08 \%$ & $0.00 \%$ & $0.85 \%$ & $27.12 \%$ & $19.49 \%$ & $51.69 \%$ & $52.54 \%$ \\
\hline 580993 & Wanhua HXP1 & $53.19 \%$ & $3.83 \%$ & $0.00 \%$ & $0.85 \%$ & $29.79 \%$ & $23.40 \%$ & $57.02 \%$ & $57.87 \%$ \\
\hline 580994 & Yuanshui CTP1 & $40.93 \%$ & $14.51 \%$ & $0.00 \%$ & $6.22 \%$ & $20.73 \%$ & $20.21 \%$ & $55.44 \%$ & $61.66 \%$ \\
\hline 580995 & Baosteel JTP1 & $42.67 \%$ & $12.93 \%$ & $1.29 \%$ & $6.47 \%$ & $22.84 \%$ & $19.83 \%$ & $55.60 \%$ & $63.36 \%$ \\
\hline 580996 & Huchang JTP1 & $43.16 \%$ & $4.27 \%$ & $2.14 \%$ & $1.28 \%$ & $20.94 \%$ & $22.22 \%$ & $47.44 \%$ & $50.85 \%$ \\
\hline 580997 & Zhaohang CMP1 & $44.29 \%$ & $1.67 \%$ & $2.23 \%$ & $1.39 \%$ & $24.79 \%$ & $19.50 \%$ & $45.96 \%$ & $49.58 \%$ \\
\hline 580998 & Jichang JTP1 & $43.78 \%$ & $18.03 \%$ & $1.29 \%$ & $5.15 \%$ & $22.75 \%$ & $21.03 \%$ & $61.80 \%$ & $68.24 \%$ \\
\hline 580999 & Wuhan steel JTP1 & $44.02 \%$ & $19.23 \%$ & $2.14 \%$ & $8.97 \%$ & $21.37 \%$ & $22.65 \%$ & $63.25 \%$ & $74.36 \%$ \\
\hline 038001 & Gangfan PGP1 & $42.42 \%$ & $18.18 \%$ & $0.61 \%$ & $4.24 \%$ & $23.94 \%$ & $18.48 \%$ & $60.61 \%$ & $65.45 \%$ \\
\hline 038002 & Wanke HRP1 & $44.51 \%$ & $5.78 \%$ & $1.73 \%$ & $2.89 \%$ & $21.97 \%$ & $22.54 \%$ & $50.29 \%$ & $54.91 \%$ \\
\hline 038003 & Hualing JTP1 & $37.00 \%$ & $15.47 \%$ & $1.79 \%$ & $2.24 \%$ & $20.63 \%$ & $16.37 \%$ & $52.47 \%$ & $56.50 \%$ \\
\hline 038005 & Shenneng JTP1 & $42.57 \%$ & $14.85 \%$ & $0.99 \%$ & $3.96 \%$ & $18.81 \%$ & $23.76 \%$ & $57.43 \%$ & $62.38 \%$ \\
\hline 038006 & Zhongji ZYP1 & $47.47 \%$ & $5.62 \%$ & $1.97 \%$ & $0.56 \%$ & $25.56 \%$ & $21.91 \%$ & $53.09 \%$ & $55.62 \%$ \\
\hline 038008 & Jiafei JTP1 & $47.04 \%$ & $6.36 \%$ & $1.69 \%$ & $2.54 \%$ & $27.97 \%$ & $19.07 \%$ & $53.39 \%$ & $57.63 \%$ \\
\hline \multicolumn{2}{|c|}{ Average } & $44.86 \%$ & $9.63 \%$ & $1.31 \%$ & $3.27 \%$ & $23.73 \%$ & $21.12 \%$ & $54.49 \%$ & $59.07 \%$ \\
\hline \multicolumn{2}{|c|}{ S\&P 500 Puts } & $5.40 \%$ & $13.20 \%$ & $2.80 \%$ & $0.00 \%$ & - & - & $18.60 \%$ & $21.40 \%$ \\
\hline
\end{tabular}


Table 4: Empirical results from testing the perfect correlation property of the $\mathbf{3 0}$ expired warrants. The correlation coefficients are computed from the time series of daily price changes. Above the dashed line are the warrants traded on the Shanghai Stock Exchange. Below the dashed line are the warrants traded on the Shenzhen Stock Exchange.

\section{Call warrants:}

\begin{tabular}{|c|c|c|c|c|c|c|}
\hline \multicolumn{2}{|c|}{ Correlation } & \multirow{2}{*}{$\begin{array}{c}\Delta \mathrm{S} \\
\Delta \text { warrant }\end{array}$} & \multirow{2}{*}{$\begin{array}{c}\Delta \mathrm{S} \\
\Delta \mathrm{BS} \text { Price }\end{array}$} & \multirow{2}{*}{$\begin{array}{c}\Delta \text { warrant } \\
\Delta \text { Index }\end{array}$} & \multirow[b]{2}{*}{ Initial trading day } & \multirow[b]{2}{*}{ Expiration day } \\
\hline Warrant Code & Warrant Name & & & & & \\
\hline 580000 & Baosteel JTB1 & 0.30 & 0.93 & 0.14 & $2005-08-22$ & $2006-08-30$ \\
\hline 580001 & Wuhan steel JTB1 & 0.57 & 0.93 & 0.22 & $2005-11-23$ & $2006-11-22$ \\
\hline 580002 & BaoSteel JTB1 & 0.84 & 0.99 & 0.50 & $2006-03-31$ & $2007-03-30$ \\
\hline 580003 & HanSteel JTB1 & 0.78 & 0.99 & 0.54 & 2006-04-05 & 2007-04-04 \\
\hline 580004 & Shouchuang JTB1 & 0.78 & 0.95 & 0.52 & $2006-04-24$ & $2007-04-23$ \\
\hline 580005 & Wanhua HXB1 & 0.75 & 0.89 & 0.59 & $2006-04-27$ & $2007-04-26$ \\
\hline 580006 & Yager QCB1 & 0.91 & 1.00 & 0.61 & $2006-05-22$ & $2007-05-21$ \\
\hline 580007 & Changdian CWB1 & 0.79 & 1.00 & 0.55 & $2006-05-25$ & $2007-05-24$ \\
\hline 580008 & Guodian JTB1 & 0.86 & 1.00 & 0.57 & 2006-09-05 & 2007-09-04 \\
\hline 580009 & Yili CWB1 & 0.87 & 1.00 & 0.61 & $2006-11-15$ & $2007-11-14$ \\
\hline 580011 & Zhonghua CWB1 & 0.88 & 1.00 & 0.62 & $2006-12-18$ & $2007-12-17$ \\
\hline 030001 & Ansteel JTC1 & 0.67 & 0.99 & 0.46 & $2005-12-05$ & $2006-12-05$ \\
\hline 031001 & Qiaocheng HQC1 & 0.91 & 1.00 & 0.27 & $2006-11-24$ & $2007-11-23$ \\
\hline 031003 & Shenfa SFC1 & 0.79 & 1.00 & 0.55 & $2007-06-29$ & $2007-12-28$ \\
\hline
\end{tabular}




\section{Put warrants:}

\begin{tabular}{|c|c|c|c|c|c|c|}
\hline \multicolumn{2}{|c|}{ Correlation } & \multirow{2}{*}{$\begin{array}{c}\Delta \mathrm{S} \\
\Delta \text { warrant }\end{array}$} & \multirow{2}{*}{$\begin{array}{c}\Delta \mathrm{S} \\
\Delta \mathrm{BS} \text { Price }\end{array}$} & \multirow{2}{*}{$\begin{array}{c}\Delta \text { warrant } \\
\Delta \text { Index }\end{array}$} & \multirow[b]{2}{*}{ Initial trading day } & \multirow[b]{2}{*}{ Expiration day } \\
\hline Warrant Code & Warrant Name & & & & & \\
\hline 580990 & Maotai JCP1 & -0.00 & -0.43 & -0.06 & $2006-05-30$ & 2007-05-29 \\
\hline 580991 & Haier JTP1 & -0.06 & -0.16 & -0.14 & $2006-05-17$ & $2007-05-16$ \\
\hline 580992 & Yager QCP1 & -0.04 & -0.29 & -0.11 & $2006-05-22$ & $2007-05-21$ \\
\hline 580993 & Wanhua HXP1 & 0.13 & -0.60 & 0.09 & $2006-04-27$ & $2007-04-26$ \\
\hline 580994 & Yuanshui CTP1 & 0.02 & -0.81 & 0.08 & 2006-04-19 & $2007-02-12$ \\
\hline 580995 & Baosteel JTP1 & 0.03 & -0.44 & -0.07 & $2006-03-31$ & $2007-03-30$ \\
\hline 580996 & Huchang JTP1 & 0.10 & -0.46 & 0.10 & 2006-03-07 & 2007-03-06 \\
\hline 580997 & Zhaohang CMP1 & -0.03 & -0.16 & -0.06 & 2006-03-02 & 2007-09-01 \\
\hline 580998 & Jichang JTP1 & -0.14 & -0.82 & -0.10 & $2005-12-23$ & $2006-12-22$ \\
\hline 580999 & Wuhan steel JTP1 & 0.18 & -0.76 & -0.01 & $2005-11-23$ & $2006-11-22$ \\
\hline 038001 & Gangfan PGP1 & -0.16 & -0.67 & -0.12 & $2005-11-04$ & $2007-05-03$ \\
\hline 038002 & Wanke HRP1 & -0.02 & -0.56 & 0.03 & $2005-12-05$ & 2006-09-04 \\
\hline 038003 & Hualing JTP1 & -0.19 & -0.28 & -0.13 & 2006-03-02 & 2008-03-01 \\
\hline 038005 & Shenneng JTP1 & -0.08 & -0.89 & 0.06 & $2006-04-27$ & $2006-10-26$ \\
\hline 038006 & Zhongji ZYP1 & -0.08 & -0.16 & -0.22 & $2006-05-25$ & $2007-11-23$ \\
\hline 038008 & Jiafei JTP1 & 0.05 & -0.36 & -0.08 & $2006-06-30$ & $2007-06-29$ \\
\hline
\end{tabular}


Table 5: The sign and magnitude of cumulated delta-hedged gains. We compute the cumulated gains on delta-hedged portfolios: (1) a long call position, hedged by a short position in the underlying stock, or (2) a long put position, hedged by a long position in the underlying stock, with the net investment earning the risk-free rate. For example, the cumulated delta-hedged gain of a call warrant is given by

$$
\pi(t, t+\tau)=C_{t+\tau}-C_{t}-\sum_{n=0}^{N-1} \Delta_{t_{n}}\left(S_{t_{n+1}}-S_{t_{n}}\right)-\sum_{n=0}^{N-1} r\left(C_{t_{n}}-\Delta_{t_{n}} S_{t_{n}}\right) \frac{\tau}{N}
$$

which is used by Bakshi and Kapadia (2003b). The portfolio is re-balanced daily $(\tau / N=1 / 242)$, and the $\Delta_{t_{n}}$ is computed as the Black-Scholes hedge ratio, evaluated at the historical volatility, which has been defined in Section IV. Column four is the cash amount of the gains. Column five and six are the relative amount of the gains, normalized by the initial underlying stock price and warrant price. Column seven is the occurrence frequency of negative daily gains over the lifetime of the warrant.

\section{Call warrants:}

\begin{tabular}{|c|c|c|c|c|c|c|}
\hline Wrt Code & Wrt Name & OBS & $\begin{array}{c}\text { Cumulated } \\
\text { Delta-Hedged } \\
\text { Gains }(\pi)\end{array}$ & $\begin{array}{l}\text { Magnitude of } \\
\qquad \pi / \mathrm{S}\end{array}$ & $\begin{array}{l}\text { Magnitude of } \\
\qquad \pi / \mathrm{C}\end{array}$ & $\begin{array}{l}\text { Frequency of } \\
\qquad d \pi<0\end{array}$ \\
\hline 580000 & Baosteel JTB1 & 242 & -0.60 & $-12.89 \%$ & $-47.35 \%$ & $56.20 \%$ \\
\hline 580001 & Wuhan steel JTB1 & 234 & -0.71 & $-25.73 \%$ & $-86.70 \%$ & $55.13 \%$ \\
\hline 580002 & BaoSteel JTB1 & 232 & -0.47 & $-22.58 \%$ & $-81.18 \%$ & $52.16 \%$ \\
\hline 580003 & HanSteel JTB1 & 233 & -0.46 & $-14.94 \%$ & $-57.91 \%$ & $50.64 \%$ \\
\hline 580004 & Shouchuang JTB1 & 233 & -1.11 & $-24.84 \%$ & $-69.60 \%$ & $57.08 \%$ \\
\hline 580005 & Wanhua HXB1 & 235 & 1.97 & $11.97 \%$ & $19.18 \%$ & $50.64 \%$ \\
\hline 580006 & Yager QCB1 & 236 & -0.82 & $-12.00 \%$ & $-24.41 \%$ & $52.97 \%$ \\
\hline 580007 & Changdian CWB1 & 234 & -1.71 & $-24.25 \%$ & $-53.16 \%$ & $55.56 \%$ \\
\hline 580008 & Guodian JTB1 & 229 & -0.93 & $-17.65 \%$ & $-52.20 \%$ & $51.97 \%$ \\
\hline 580009 & Yili CWB1 & 235 & -3.06 & $-16.77 \%$ & $-23.91 \%$ & $53.19 \%$ \\
\hline 580011 & Zhonghua CWB1 & 231 & -1.31 & $-18.42 \%$ & $-54.17 \%$ & $51.95 \%$ \\
\hline 030001 & Ansteel JTC1 & 234 & -0.63 & $-15.06 \%$ & $-39.42 \%$ & $57.27 \%$ \\
\hline 031001 & Qiaocheng HQC1 & 219 & -3.34 & $-18.80 \%$ & $-28.09 \%$ & $47.03 \%$ \\
\hline 031003 & Shenfa SFC1 & 118 & -6.22 & $-22.62 \%$ & $-40.84 \%$ & $53.39 \%$ \\
\hline \multicolumn{3}{|c|}{ Mean } & -1.39 & $-16.75 \%$ & $-45.70 \%$ & $53.23 \%$ \\
\hline \multicolumn{3}{|c|}{ Median } & -0.87 & $-18.04 \%$ & $-49.78 \%$ & $53.08 \%$ \\
\hline \multicolumn{3}{|c|}{ Standard Deviation } & 1.87 & 0.09 & 0.27 & 0.03 \\
\hline
\end{tabular}


Put warrants:

\begin{tabular}{l|c|c|c|c|c|c}
\hline Wrt Code & Wrt Name & OBS & $\begin{array}{c}\text { Cumulated } \\
\text { Delta-Hedged } \\
\text { Gains }(\pi)\end{array}$ & $\begin{array}{c}\text { Magnitude of } \\
\pi / \mathrm{S}\end{array}$ & $\begin{array}{c}\text { Magnitude of } \\
\pi / \mathrm{P}\end{array}$ & $\begin{array}{c}\text { Frequency of } \\
d \pi<0\end{array}$ \\
\hline 580990 & Maotai JCP1 & 233 & -0.78 & $-1.62 \%$ & $-51.34 \%$ & $49.36 \%$ \\
580991 & Haier JTP1 & 230 & -0.84 & $-17.73 \%$ & $-80.11 \%$ & $50.43 \%$ \\
580992 & Yager QCP1 & 236 & -0.79 & $-11.61 \%$ & $-82.09 \%$ & $48.31 \%$ \\
580993 & Wanhua HXP1 & 235 & -2.31 & $-14.06 \%$ & $-70.80 \%$ & $47.66 \%$ \\
580994 & Yuanshui CTP1 & 193 & -0.45 & $-10.57 \%$ & $-35.29 \%$ & $51.30 \%$ \\
580995 & Baosteel JTP1 & 232 & -0.18 & $-8.73 \%$ & $-30.11 \%$ & $47.84 \%$ \\
580996 & Huchang JTP1 & 234 & 0.32 & $2.69 \%$ & $16.73 \%$ & $51.28 \%$ \\
580997 & Zhaohang CMP1 & 359 & 0.07 & $1.10 \%$ & $12.14 \%$ & $49.58 \%$ \\
580998 & Jichang JTP1 & 233 & -1.04 & $-15.42 \%$ & $-56.42 \%$ & $53.65 \%$ \\
580999 & Wuhan steel JTP1 & 234 & -0.84 & $-30.28 \%$ & $-72.30 \%$ & $51.28 \%$ \\
038001 & Gangfan PGP1 & 330 & -0.96 & $-29.08 \%$ & $-49.29 \%$ & $47.88 \%$ \\
038002 & Wanke HRP1 & 173 & -0.27 & $-7.25 \%$ & $-31.61 \%$ & $53.18 \%$ \\
038003 & Hualing JTP1 & 446 & -0.29 & $-8.08 \%$ & $-17.87 \%$ & $49.55 \%$ \\
038005 & Shenneng JTP1 & 101 & -0.73 & $-11.61 \%$ & $-50.14 \%$ & $58.42 \%$ \\
038006 & Zhongji ZYP1 & 356 & -2.28 & $-16.28 \%$ & $-85.89 \%$ & $46.07 \%$ \\
038008 & Jiafei JTP1 & 236 & -2.05 & $-10.11 \%$ & $-70.32 \%$ & $46.61 \%$ \\
\hline & Mean & & -0.84 & $-11.79 \%$ & $-47.17 \%$ & $50.15 \%$ \\
& Standard Deviation & & -0.79 & $-11.09 \%$ & $-50.74 \%$ & $49.57 \%$ \\
& Median & 0.78 & 0.09 & 0.31 & 0.03 \\
\hline
\end{tabular}

\section{Call and Put warrants in total:}

\begin{tabular}{c|c|c|c|c}
\hline All warrants & $\begin{array}{c}\text { Cumulated } \\
\text { Delta-Hedged } \\
\text { Gains }(\pi)\end{array}$ & $\begin{array}{c}\text { Magnitude of } \\
\pi / \mathrm{S}\end{array}$ & $\begin{array}{c}\text { Magnitude of } \\
\pi / \text { warrant }\end{array}$ & $\begin{array}{c}\text { Frequency of } \\
d \pi<0\end{array}$ \\
\hline Mean & -1.09 & $-14.11 \%$ & $-46.48 \%$ & $51.59 \%$ \\
Median & -0.80 & $-15.00 \%$ & $-50.74 \%$ & $51.29 \%$ \\
Standard Deviation & 1.40 & 0.09 & 0.29 & 0.03 \\
\hline
\end{tabular}


Table 6: Panel regressions on daily delta-hedged gains against possible explanatory variables. This table reports the coefficients estimates and Newey-West (1987) t-statistics with 21 lags (in square brackets) of the panel data regressions. GAINS is the daily gains of delta-hedged warrants pooled from 14 call warrants or 16 put warrants; IdxRt is market index return; IdxVol is daily market index volatility; SVol is the daily underlying stock volatility; TrdValue is the warrant trading value. We report the empirical results in two panels (one for calls and the other for puts). Statistical significance at the $1 \%, 5 \%$ and $10 \%$ levels are denoted by $* * *, * *$ and $*$, respectively.

(1) $\mathrm{GAINS}=\alpha+\beta_{1} \mathrm{IdxRt}+\varepsilon_{1}$

(2) GAINS $=\alpha+\beta_{2} \mathrm{IdxVol}+\varepsilon_{2}$

(3) GAINS $=\alpha+\beta_{3} \mathrm{SVol}+\varepsilon_{3}$

(4) GAINS $=\alpha+\beta_{4}$ TrdValue $+\varepsilon_{4}$

(5) GAINS $=\alpha+\beta_{1} \mathrm{IdxRt}+\beta_{2} \mathrm{IdxVol}+\beta_{3} \mathrm{SVol}+\beta_{4} \operatorname{TrdValue}+\varepsilon_{1234}$

\section{Call warrants:}

\begin{tabular}{|c|c|c|c|c|c|}
\hline Crino & (1) & (2) & (3) & $\begin{array}{c}\text { (4) } \\
\text { Tredvalue }\end{array}$ & (5) \\
\hline \multirow{3}{*}{ a } & 000 & $0 \cap 6 * *$ & $0 \Omega 1$ & $0 \Omega 0$ & $00 ?$ \\
\hline & 0.00 & -0.00 & -0.01 & -0.00 & -0.02 \\
\hline & {$[0.05]$} & {$[-3.73]$} & {$[-0.91]$} & {$[-0.01]$} & {$[-1.34]$} \\
\hline \multirow[t]{2}{*}{$\beta 1$ (IdxRt) } & $-1.79 * * *$ & & & & $-1.59 * *$ \\
\hline & {$[-2.80]$} & & & & {$[-2.37]$} \\
\hline \multirow[t]{2}{*}{$\beta 2(\mathrm{Idx}$ Vol $)$} & & $3.54 * * *$ & & & $4.54 * * *$ \\
\hline & & [3.32] & & & {$[3.51]$} \\
\hline \multirow[t]{2}{*}{$\beta 3(\mathrm{SVol})$} & & & 0.21 & & $-1.36 * *$ \\
\hline & & & {$[0.40]$} & & {$[-2.04]$} \\
\hline \multirow[t]{2}{*}{$\beta 4$ (TrdValue) } & & & & -0.01 & -0.01 \\
\hline & & & & {$[-0.88]$} & {$[-0.65]$} \\
\hline \# warrants & 14 & 14 & 14 & 14 & 14 \\
\hline OBS & 3145 & 3145 & 3145 & 3145 & 3145 \\
\hline \multicolumn{6}{|l|}{ Put warrants: } \\
\hline \multirow[b]{2}{*}{ Gains } & (1) & (2) & (3) & (4) & (5) \\
\hline & IdxRt & IdxVol & SVol & TrdValue & All \\
\hline \multirow[t]{2}{*}{$a$} & -0.00 & -0.00 & $-0.01 * * *$ & $-0.01 * * *$ & $-0.01 *$ \\
\hline & {$[-1.29]$} & {$[-0.39]$} & {$[-2.77]$} & {$[-3.37]$} & {$[-1.77]$} \\
\hline \multirow[t]{2}{*}{$\beta 1$ (IdxRt) } & 0.05 & & & & 0.07 \\
\hline & {$[0.18]$} & & & & {$[0.26]$} \\
\hline \multirow[t]{2}{*}{$\beta 2(\mathrm{Idx} V o l)$} & & -0.10 & & & $-1.18 * *$ \\
\hline & & {$[-0.22]$} & & & {$[-2.06]$} \\
\hline \multirow[t]{2}{*}{$\beta 3$ (SVol) } & & & $0.42 *$ & & $0.71 * * *$ \\
\hline & & & [1.94] & & [2.75] \\
\hline \multirow[t]{2}{*}{$\beta 4$ (TrdValue) } & & & & $0.01 *$ & $0.01 *$ \\
\hline & & & & [1.69] & {$[1.74]$} \\
\hline \# warrants & 16 & 16 & 16 & 16 & 16 \\
\hline OBS & 4061 & 4061 & 4061 & 4061 & 4061 \\
\hline
\end{tabular}


Figure 1: The market prices, Black-Scholes prices and trading value of Baosteel JTB1 (580000)

Figure 1a: A comparison between market prices of a warrant and its Black-Scholes prices with historical volatility. The Black-Scholes price is computed from the Black-Scholes formula with historical volatility. The historical volatility on any date is computed as the standard deviation of log stock price returns in a moving window of fixed length. The length of the moving window is determined as the time to expiration of the warrant at its initial trading date.

Market Price vs Black Scholes Price

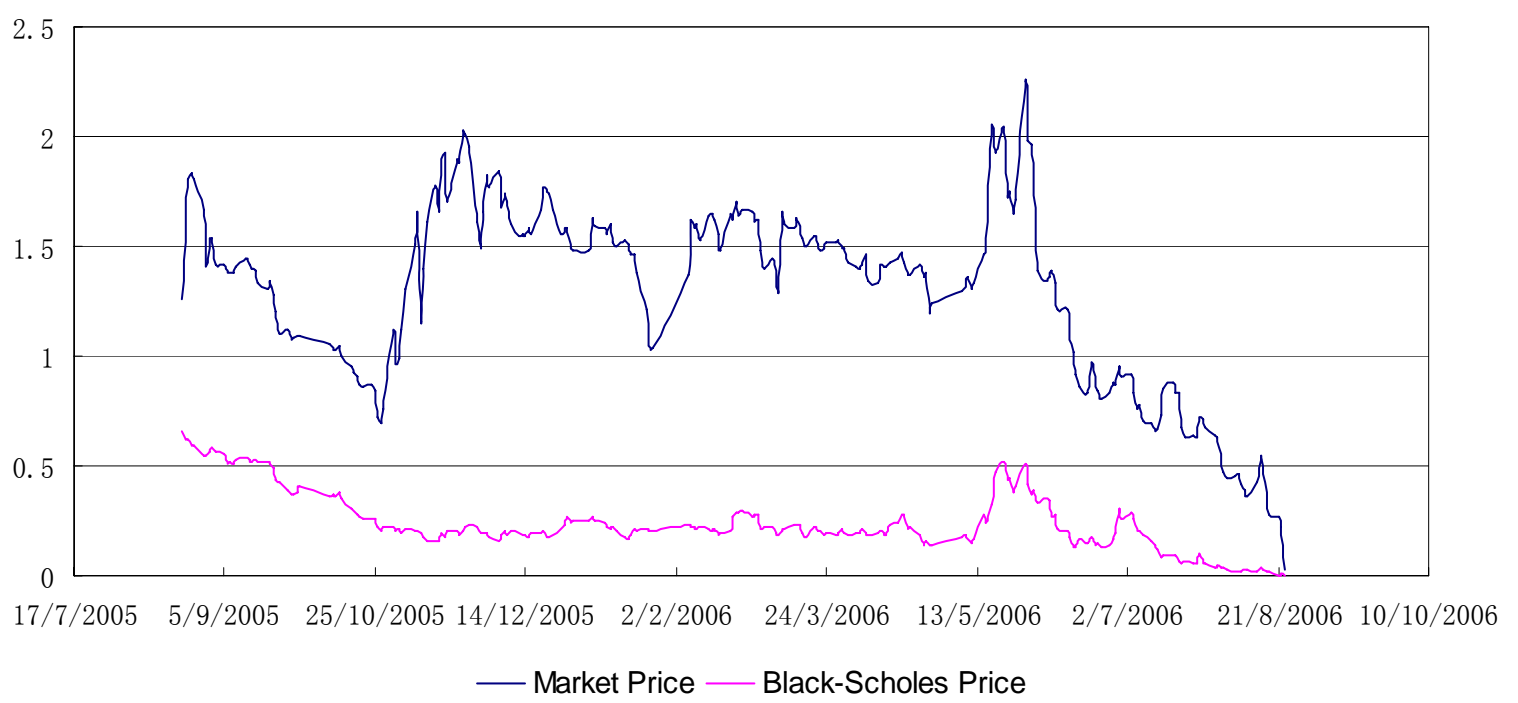

Figure 1b: A comparison between the daily trading value of a warrant and that of its underlying stock. The unit of trading value is CNY. The daily trading value of a warrant is consistently higher than that of its underlying stock

Underlying and Warrant Trading Value

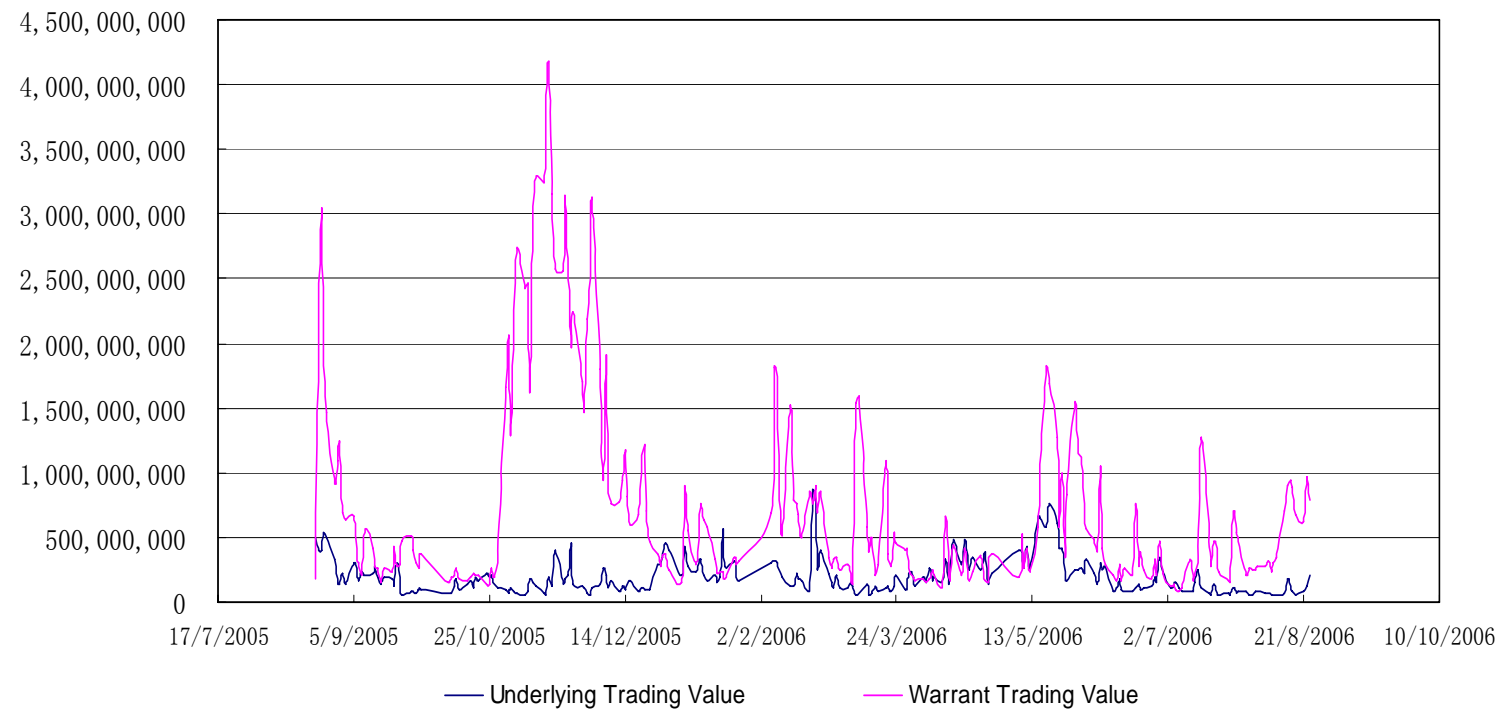


Figure 2: The market prices, Black-Scholes prices and trading value of Zhaohang CMP1 (580997). The deeply out-of-the-money put warrant is heavily over-priced in the few months before the maturity date. Its price dynamics is highly correlated with its trading values.

Market Price vs Black Scholes Price

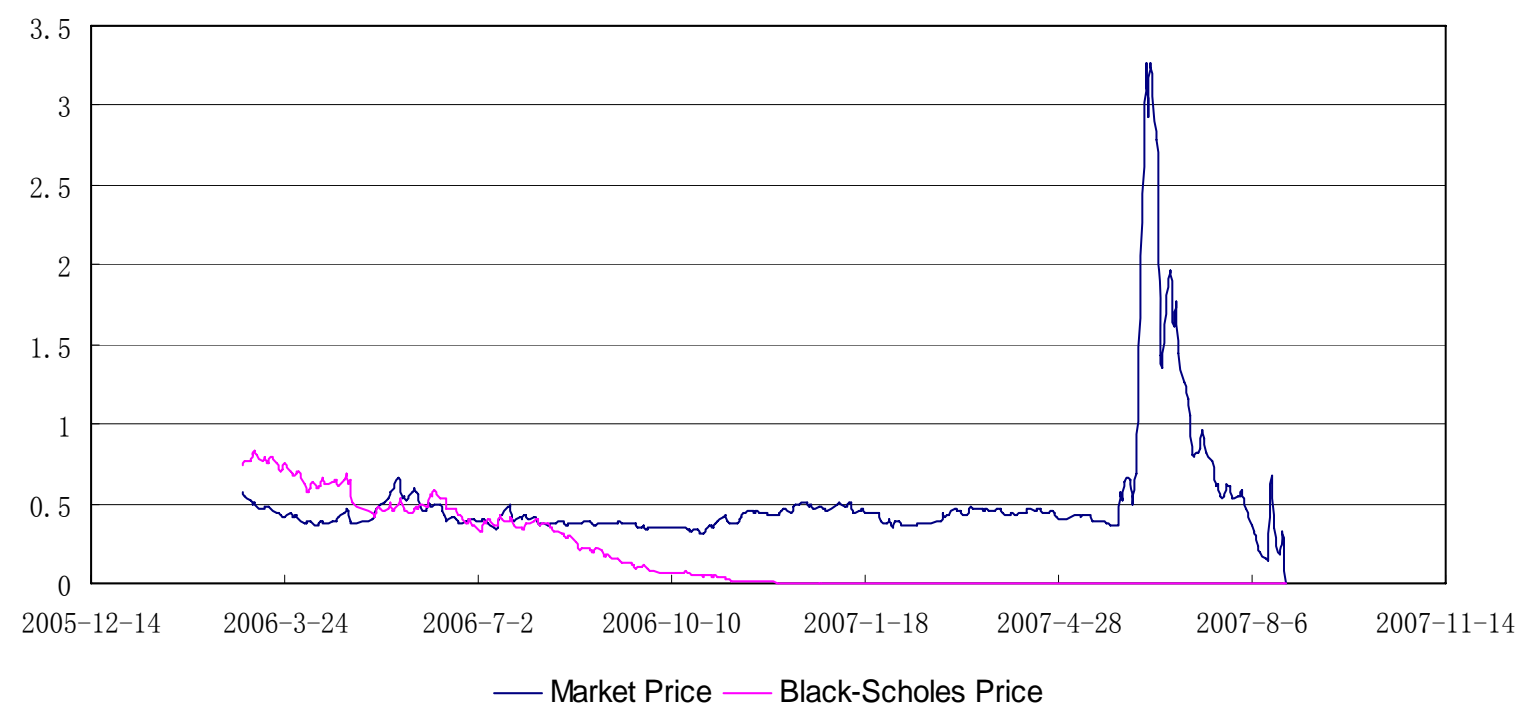

Underlying and Warrant Trading Value

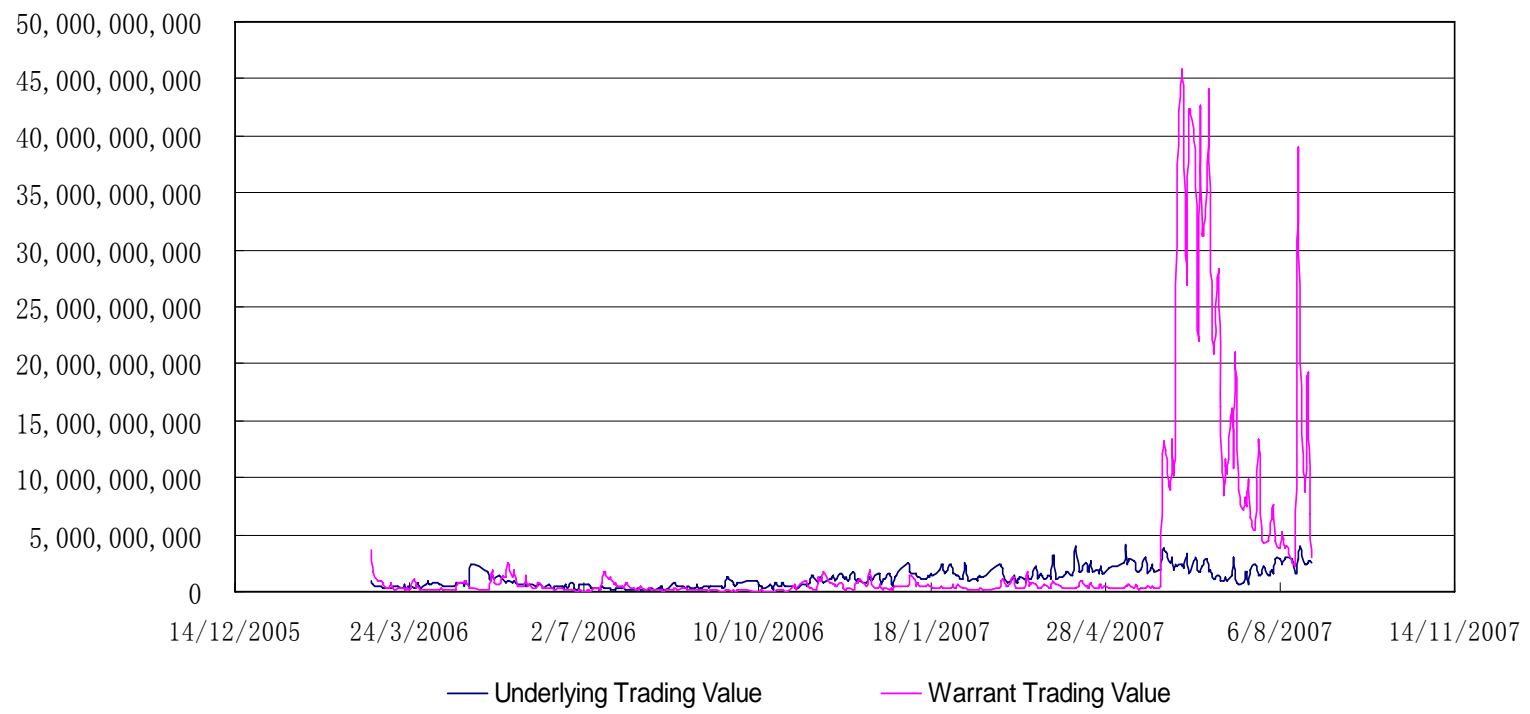


Figure 3: Time value and implied volatility of Zhonghua CWB1 (580011)

Figure 3a: A comparison between the time values of warrants computed from their market prices and those computed from their Black-Scholes prices. Time value is defined as the difference between the price of a warrant and its intrinsic value. The intrinsic value of a warrant is $\max \left(S-K e^{-r \tau}, 0\right)$ for call, and $\max \left(K e^{-r \tau}-S, 0\right)$ for put.

Time Value Comparision

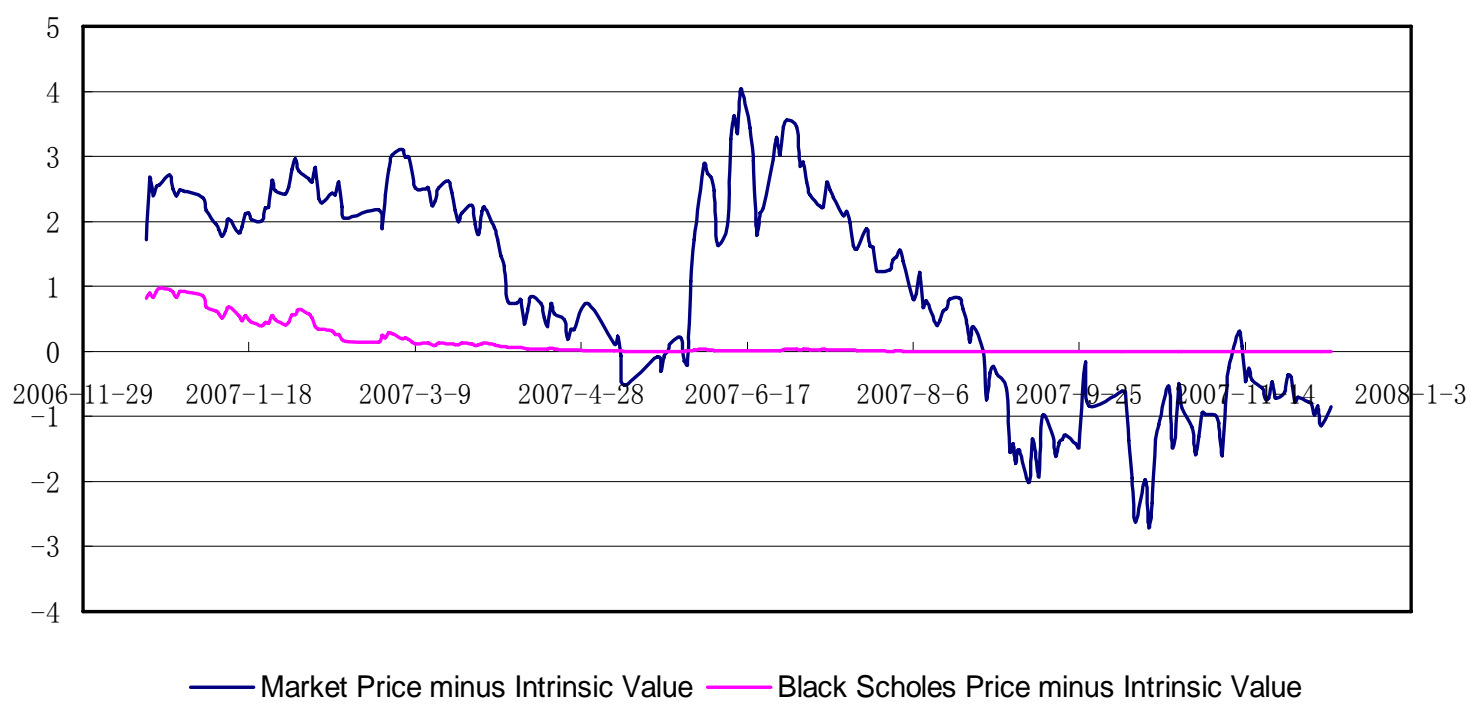

Figure 3b: A comparison between implied volatility and historical volatility. Implied volatility is defined as the one that equals the Black-Scholes price to the market price. The historical volatility on any date is computed as the standard deviation of log stock price returns in a moving window of fixed length. The length of the moving window is determined as the time to expiration of the warrant at its initial trading date. The broken line indicates that the implied volatility cannot be computed on these days due to the fact that the market prices are lower than the intrinsic values.

Historical Volatility vs Implied Volatility

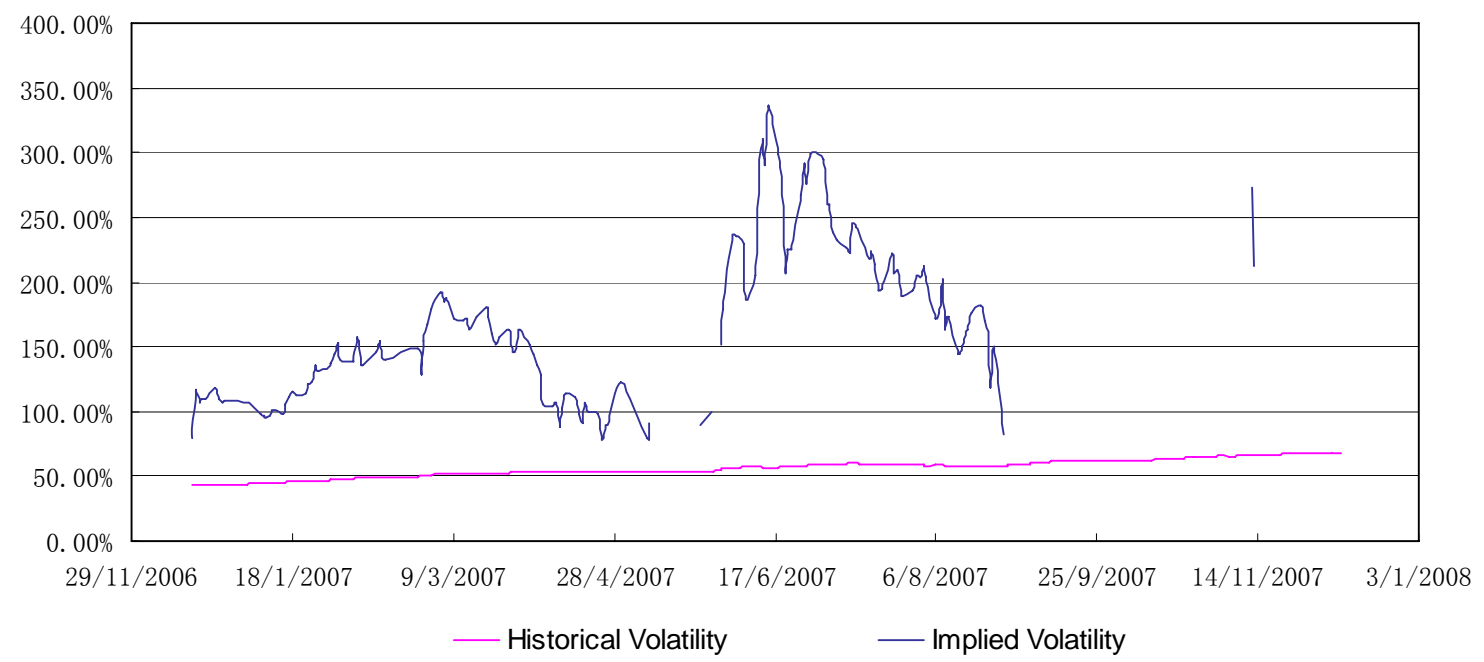


Appendix: Overview of the Chinese warrant market. Up until March 14, 2008, there were totally 47 warrants traded on the Shanghai and Shenzhen markets. Among these warrants, 30 were expired and 17 were still being traded at that point in time. This table shows, for each of the 47 warrants, its trading code (ticker), name, underlying stock code (ticker), underlying stock name, exchanges (in column 6, with header "Ex", where "SH" stands for Shanghai Stock Exchange, and "SZ" for Shenzhen Stock Exchange), categories (in column 7, with header "C/P", where "C" stands for call and "P” for put; in column 8, with header "A/B/E", where "A" stands for American, "E” for European, and "B" for Bermuda; in column 9, with header "Covered/Equity", meaning covered warrant or equity warrant), maturity (including the start day for trading and end day for exercise; column 12, with header "TTM (days)", which stands for days to maturity at the initial issuance time; column 13, with header "Exp Y/N", which means whether the warrant was expired or not up until March 14, 2008), initial strike price and exercise ratio and the ones updated to March 14, 2008.

\begin{tabular}{|c|c|c|c|c|c|c|c|c|c|c|c|c|c|c|c|}
\hline \multirow[b]{3}{*}{ \# } & \multirow{3}{*}{$\begin{array}{c}\text { Warrant } \\
\text { code }\end{array}$} & \multirow[b]{3}{*}{ Warrant Name } & \multirow[b]{3}{*}{ Stock Name } & \multirow[b]{3}{*}{ Ex } & \multicolumn{3}{|c|}{ Category } & \multicolumn{4}{|c|}{ Maturity } & \multirow{2}{*}{\multicolumn{2}{|c|}{$\begin{array}{r}\text { Initial items } \\
\text { Exercise }\end{array}$}} & \multirow{2}{*}{\multicolumn{2}{|c|}{$\begin{array}{r}\text { Updated items } \\
\text { Exercise }\end{array}$}} \\
\hline & & & & & & & Covered & Start date & End date for & TTM & $\operatorname{Exp}$ & & & & \\
\hline & & & & & $\mathrm{C} / \mathrm{P}$ & $\mathrm{A} / \mathrm{B} / \mathrm{E}$ & E / Equity & for trading & exercise & (days) & $\mathrm{Y} / \mathrm{N}$ & Strike & Ratio & Strike & Ratio \\
\hline 1 & 580000 & Baosteel JTB1 & 600019 Baoshan Iron \& Steel Co., Ltd. & $\mathrm{SH}$ & $\mathrm{C}$ & $\mathrm{E}$ & Covered & $2005-08-22$ & 2006-08-30 & 378 & $\mathrm{Y}$ & 4.50 & 1 & 4.20 & 1 \\
\hline 2 & 580001 & Wuhan steel JTB1 & 600005 Wuhan Iron and Steel Co., Ltd. & $\mathrm{SH}$ & $\mathrm{C}$ & $\mathrm{E}$ & Covered & 2005-11-23 & $2006-11-22$ & 365 & $\mathrm{Y}$ & 2.90 & 1 & 2.62 & 1 \\
\hline 3 & 580002 & Baosteel JTB1 & 600010 Inner Mongolia BaoTou Steel Union Co., Ltd. & $\mathrm{SH}$ & $\mathrm{C}$ & $\mathrm{E}$ & Covered & 2006-03-31 & $2007-03-30$ & 365 & $\mathrm{Y}$ & 2.00 & 1 & 1.94 & 1 \\
\hline 4 & 580003 & Hansteel JTB1 & 600001 Handan Iron \& Steel Co., Ltd. (HDIS) & $\mathrm{SH}$ & $\mathrm{C}$ & $\mathrm{E}$ & Covered & 2006-04-05 & 2007-04-04 & 365 & $\mathrm{Y}$ & 2.80 & 1 & 2.73 & 1 \\
\hline 5 & 580004 & Shouchuang JTB1 & 600008 Beijing Capital Co., Ltd. & $\mathrm{SH}$ & $\mathrm{C}$ & $\mathrm{E}$ & Covered & 2006-04-24 & $2007-04-23$ & 365 & $\mathrm{Y}$ & 4.55 & 1 & 4.40 & 1 \\
\hline 6 & 580005 & Wanhua HXB1 & 600309 Yantai Wanhua Polyurethanes Co., Ltd. & $\mathrm{SH}$ & $\mathrm{C}$ & $\mathrm{E}$ & Covered & $2006-04-27$ & $2007-04-26$ & 365 & $\mathrm{Y}$ & 9.00 & 1 & 6.38 & 1.4097 \\
\hline 7 & 580006 & Yager QCB1 & 600177 Youngor Group Co., Ltd. & $\mathrm{SH}$ & $\mathrm{C}$ & $\mathrm{E}$ & Covered & $2006-05-22$ & $2007-05-21$ & 365 & $\mathrm{Y}$ & 3.80 & 1 & 3.66 & 1 \\
\hline 8 & 580007 & Changdian CWB1 & 600900 China Yangtze Power Co., Ltd. (CYPC) & $\mathrm{SH}$ & $\mathrm{C}$ & $\mathrm{E}$ & Equity & 2006-05-25 & $2007-05-24$ & 365 & $\mathrm{Y}$ & 5.50 & 1 & 5.35 & 1 \\
\hline 9 & 580008 & Guodian JTB1 & 600795 GD Power Development Co., Ltd. & $\mathrm{SH}$ & $\mathrm{C}$ & $\mathrm{E}$ & Covered & 2006-09-05 & 2007-09-04 & 365 & $\mathrm{Y}$ & 4.80 & 1 & 4.77 & 1 \\
\hline 10 & 580009 & Yili CWB1 & 600887 Inner Mongolia Yili Industrial Group Co., Ltd. & $\mathrm{SH}$ & $\mathrm{C}$ & E & Equity & 2006-11-15 & $2007-11-14$ & 365 & $\mathrm{Y}$ & 8.00 & 1 & 7.97 & 1 \\
\hline
\end{tabular}




\begin{tabular}{|c|c|c|c|c|c|c|c|c|c|c|c|c|c|c|c|}
\hline \multirow[b]{3}{*}{ \# } & \multirow{3}{*}{$\begin{array}{c}\text { Warrant } \\
\text { code }\end{array}$} & \multirow[b]{3}{*}{ Warrant Name } & \multirow[b]{3}{*}{ Stock Name } & \multirow[b]{3}{*}{ Ex } & \multicolumn{3}{|c|}{ Category } & \multicolumn{4}{|c|}{ Maturity } & \multirow{2}{*}{\multicolumn{2}{|c|}{$\begin{array}{r}\text { Initial items } \\
\text { Exercise }\end{array}$}} & \multirow{2}{*}{\multicolumn{2}{|c|}{$\frac{\text { Updated items }}{\text { Exercise }}$}} \\
\hline & & & & & & & Covered & Start date & End date for & & Exp & & & & \\
\hline & & & & & $\mathrm{C} / \mathrm{P}$ & $\mathrm{A} / \mathrm{B} / \mathrm{E}$ & / Equity & for trading & exercise & (days) & $\mathrm{Y} / \mathrm{N}$ & Strike & Ratio & Strike & Ratio \\
\hline 11 & 580010 & Masteel CWB1 & 600808 Maanshan Iron \& Steel Company Limited & $\mathrm{SH}$ & $\mathrm{C}$ & $\mathrm{E}$ & Equity & 2006-11-29 & $2008-11-28$ & 730 & $\mathrm{~N}$ & 3.40 & 1 & 3.33 & 1 \\
\hline 12 & 580011 & Zhonghua CWB1 & 600500 Sinochem International Corporation & $\mathrm{SH}$ & $\mathrm{C}$ & E & Equity & 2006-12-18 & $2007-12-17$ & 365 & Y & 6.58 & 1 & 6.52 & 1 \\
\hline 13 & 580012 & Yunhua CWB1 & 600096 Yunnan Yuntianhua Co., Ltd. (YYTH) & $\mathrm{SH}$ & $\mathrm{C}$ & E & Equity & 2007-03-08 & 2009-03-07 & 730 & $\mathrm{~N}$ & 18.23 & 1 & 17.95 & 1 \\
\hline 14 & 580013 & Wuhan steel CWB1 & 600005 Wuhan Iron and Steel Co., Ltd. & $\mathrm{SH}$ & $\mathrm{C}$ & $\mathrm{E}$ & Equity & 2007-04-17 & 2009-04-16 & 730 & $\mathrm{~N}$ & 10.20 & 1 & 9.91 & 1 \\
\hline 15 & 580014 & Shengao CWB1 & 600548 Shenzhen Expressway Company Limited & $\mathrm{SH}$ & $\mathrm{C}$ & E & Equity & 2007-10-30 & 2009-10-29 & 730 & $\mathrm{~N}$ & 13.85 & 1 & 13.85 & 1 \\
\hline 16 & 580015 & Rizhao CWB1 & 600017 Rizhao Port Co., Ltd & $\mathrm{SH}$ & $\mathrm{C}$ & E & Equity & $2007-12-12$ & 2008-12-02 & 356 & $\mathrm{~N}$ & 14.25 & 1 & 14.25 & 1 \\
\hline 17 & 580016 & Shangqi CWB1 & 600104 SAIC Motor Corporation Ltd. & $\mathrm{SH}$ & $\mathrm{C}$ & E & Equity & 2008-01-08 & 2010-01-07 & 730 & $\mathrm{~N}$ & 27.43 & 1 & 27.43 & 1 \\
\hline 18 & 580017 & Ganyue CWB1 & 600269 Jiangxi Ganyue Expressway CO.,LTD. & $\mathrm{SH}$ & $\mathrm{C}$ & B & Equity & $2008-02-28$ & $2010-02-28$ & 731 & $\mathrm{~N}$ & 20.88 & 1 & 20.88 & 1 \\
\hline 19 & 580018 & Zhongyuan CWB1 & 600428 Cosco Shipping Company Limited & $\mathrm{SH}$ & $\mathrm{C}$ & $\mathrm{E}$ & Equity & 2008-02-26 & 2009-08-25 & 546 & $\mathrm{~N}$ & 40.38 & 0.5 & 40.38 & 0.5 \\
\hline 20 & 580019 & Shihua CWB1 & 600028 China Petroleum \& Chemical Corporation & $\mathrm{SH}$ & $\mathrm{C}$ & $\mathrm{E}$ & Equity & 2008-03-04 & 2010-03-03 & 729 & $\mathrm{~N}$ & 19.68 & 0.5 & 19.68 & 0.5 \\
\hline 21 & 580020 & Shanggang CWB1 & 600018 Shanghai International Port (Group) Co., Ltd. & $\mathrm{SH}$ & $\mathrm{C}$ & E & Equity & 2008-03-07 & 2009-03-06 & 364 & $\mathrm{~N}$ & 8.40 & 1 & 8.40 & 1 \\
\hline 22 & 580989 & Nanhang JTP1 & 600029 China Southern Airlines Company Limited & $\mathrm{SH}$ & $\mathrm{P}$ & E & Covered & 2007-06-21 & 2008-06-20 & 365 & $\mathrm{~N}$ & 7.43 & 0.5 & 7.43 & 0.5 \\
\hline 23 & 580990 & Maotai JCP1 & 600519 Kweichow Moutai Co., Ltd. & $\mathrm{SH}$ & $\mathrm{P}$ & E & Covered & 2006-05-30 & $2007-05-29$ & 365 & $\mathrm{Y}$ & 30.30 & 0.25 & 30.30 & 0.25 \\
\hline 24 & 580991 & Haier JTP1 & 600690 Qingdao Haier Co., Ltd. & $\mathrm{SH}$ & $\mathrm{P}$ & E & Covered & 2006-05-17 & 2007-05-16 & 365 & $\mathrm{Y}$ & 4.39 & 1 & 4.29 & 1 \\
\hline 25 & 580992 & Yager QCP1 & 600177 Youngor Group Co., Ltd. & $\mathrm{SH}$ & $\mathrm{P}$ & $\mathrm{E}$ & Covered & 2006-05-22 & $2007-05-21$ & 365 & $\mathrm{Y}$ & 4.25 & 1 & 4.09 & 1 \\
\hline 26 & 580993 & Wanhua HXP1 & 600309 Yantai Wanhua Polyurethanes Co., Ltd. & $\mathrm{SH}$ & $\mathrm{P}$ & E & Covered & 2006-04-27 & 2007-04-26 & 365 & $\mathrm{Y}$ & 13.00 & 1 & 9.22 & 1.4097 \\
\hline 27 & 580994 & Yuanshui CTP1 & 600649 Shanghai Municipal Raw Water Co., Ltd. & $\mathrm{SH}$ & $\mathrm{P}$ & $\mathrm{E}$ & Covered & 2006-04-19 & 2007-02-12 & 300 & $\mathrm{Y}$ & 5.00 & 1 & 4.90 & 1 \\
\hline 28 & 580995 & Baosteel JTP1 & 600010 Inner Mongolia BaoTou Steel Union Co., Ltd. & $\mathrm{SH}$ & $\mathrm{P}$ & E & Covered & 2006-03-31 & 2007-03-30 & 365 & $\mathrm{Y}$ & 2.45 & 1 & 2.37 & 1 \\
\hline 29 & 580996 & Huchang JTP1 & 600009 Shanghai International Airport Co., Ltd. (SIA) & $\mathrm{SH}$ & $\mathrm{P}$ & E & Covered & 2006-03-07 & 2007-03-06 & 365 & $\mathrm{Y}$ & 13.60 & 1 & 13.36 & 1 \\
\hline
\end{tabular}




\begin{tabular}{|c|c|c|c|c|c|c|c|c|c|c|c|c|c|c|c|}
\hline \multirow[b]{3}{*}{ \# } & \multirow{3}{*}{$\begin{array}{l}\text { Warrant } \\
\text { code }\end{array}$} & \multirow[b]{3}{*}{ Warrant Name } & \multirow[b]{3}{*}{ Stock Name } & \multirow[b]{3}{*}{ Ex } & \multicolumn{3}{|c|}{ Category } & \multicolumn{4}{|c|}{ Maturity } & \multirow{2}{*}{\multicolumn{2}{|c|}{$\begin{array}{r}\text { Initial items } \\
\text { Exercise }\end{array}$}} & \multirow{2}{*}{\multicolumn{2}{|c|}{$\begin{array}{r}\text { Updated items } \\
\text { Exercise }\end{array}$}} \\
\hline & & & & & & & Covered & Start date & End date & TTM & & & & & \\
\hline & & & & & $\mathrm{C} / \mathrm{P}$ & $\mathrm{A} / \mathrm{B} / \mathrm{E}$ & / Equity & for trading & for exercise & (days) & $\mathrm{Y} / \mathrm{N}$ & Strike & Ratio & Strike & Ratio \\
\hline 30 & 580997 & Zhaohang CMP1 & 600036 China Merchants Bank Co., Ltd. & $\mathrm{SH}$ & $\mathrm{P}$ & E & Covered & 2006-03-02 & 2007-09-01 & 549 & $\mathrm{Y}$ & 5.65 & 1 & 5.45 & 1 \\
\hline 31 & 580998 & Jichang JTP1 & 600004 Guangzhou Baiyun International Airport Co., Ltd. & $\mathrm{SH}$ & $\mathrm{P}$ & A & Covered & $2005-12-23$ & $2006-12-22$ & 365 & $\mathrm{Y}$ & 7.00 & 1 & 6.90 & 1 \\
\hline 32 & 580999 & Wuhan steel JTP1 & 600005 Wuhan Iron and Steel Co., Ltd. & $\mathrm{SH}$ & $\mathrm{P}$ & $\mathrm{E}$ & Covered & $2005-11-23$ & $2006-11-22$ & 365 & $\mathrm{Y}$ & 3.13 & 1 & 2.83 & 1 \\
\hline 33 & 030001 & Ansteel JTC1 & 000898 Angang Steel Company Limited & SZ & $\mathrm{C}$ & E & Covered & $2005-12-05$ & 2006-12-05 & 366 & Y & 3.60 & 1 & 3.39 & 1 \\
\hline 34 & 030002 & Wuliang YGC1 & 000858 Wuliangye Yibin Co., Ltd. & SZ & $\mathrm{C}$ & B & Covered & 2006-04-03 & 2008-04-02 & 731 & $\mathrm{~N}$ & 6.93 & 1 & 4.90 & 1.4023 \\
\hline 35 & 031001 & Qiaocheng HQC1 & 000069 Shenzhen Overseas Chinese Town Holding Company & SZ & $\mathrm{C}$ & B & Equity & $2006-11-24$ & $2007-11-23$ & 365 & $\mathrm{Y}$ & 7.00 & 1 & 6.96 & 1 \\
\hline 36 & 031002 & Gangfan GFC1 & 000629 Panzhihua New Steel \& Vanadium Company Limited & SZ & $\mathrm{C}$ & B & Equity & $2006-12-12$ & $2008-12-11$ & 730 & $\mathrm{~N}$ & 3.95 & 1 & 3.27 & 1.209 \\
\hline 37 & 031003 & Shenfa SFC1 & 000001 Shenzhen Development Bank Co., Ltd. & SZ & $\mathrm{C}$ & $\mathrm{B}$ & Equity & 2007-06-29 & $2007-12-28$ & 183 & Y & 19.00 & 1 & 19.00 & 1 \\
\hline 38 & 031004 & Shenfa SFC2 & 000001 Shenzhen Development Bank Co., Ltd. & SZ & $\mathrm{C}$ & B & Equity & 2007-06-29 & 2008-06-27 & 365 & $\mathrm{~N}$ & 19.00 & 1 & 19.00 & 1 \\
\hline 39 & 031005 & Guoan GAC1 & 000839 CITIC Guoan Information Industry Co., Ltd. & SZ & $\mathrm{C}$ & E & Equity & $2007-09-25$ & $2009-09-25$ & 731 & $\mathrm{~N}$ & 35.50 & 0.5 & 35.50 & 0.5 \\
\hline 40 & 031006 & Zhongxing ZXC1 & 000063 ZTE Corporation & SZ & $\mathrm{C}$ & E & Equity & $2008-02-22$ & $2010-02-21$ & 730 & $\mathrm{~N}$ & 78.13 & 0.5 & 78.13 & 0.5 \\
\hline 41 & 038001 & Gangfan PGP1 & 000629 Panzhihua New Steel \& Vanadium Company Limited & SZ & $\mathrm{P}$ & $\mathrm{E}$ & Covered & 2005-11-04 & 2007-05-03 & 546 & $\mathrm{Y}$ & 4.85 & 1 & 3.16 & 1.5349 \\
\hline 42 & 038002 & Wanke HRP1 & 000002 China Vanke Co., Ltd. & SZ & $\mathrm{P}$ & B & Covered & $2005-12-05$ & 2006-09-04 & 274 & Y & 3.73 & 1 & 3.64 & 1 \\
\hline 43 & 038003 & Hualing JTP1 & 000932 Hunan Valin Steel Tube \& Wire Co., Ltd. & SZ & $P$ & E & Covered & 2006-03-02 & 2008-03-01 & 731 & Y & 4.90 & 1 & 4.72 & 1 \\
\hline 44 & 038004 & Wuliang YGP1 & 000858 Wuliangye Yibin Co., Ltd. & SZ & $\mathrm{P}$ & B & Covered & 2006-04-03 & 2008-04-02 & 731 & $\mathrm{~N}$ & 7.96 & 1 & 5.63 & 1.4023 \\
\hline 45 & 038005 & Shenneng JTP1 & 000027 Shenzhen Energy Investment Co., Ltd. (SEIC) & SZ & $\mathrm{P}$ & $\mathrm{B}$ & Covered & 2006-04-27 & $2006-10-26$ & 183 & $\mathrm{Y}$ & 7.12 & 1 & 6.69 & 1 \\
\hline 46 & 038006 & Zhongji ZYP1 & 000039 China International Marine Containers (Group) Co., Ltd. & SZ & $\mathrm{P}$ & $\mathrm{B}$ & Covered & $2006-05-25$ & $2007-11-23$ & 548 & $\mathrm{Y}$ & 10.00 & 1 & 7.30 & 1.37 \\
\hline 47 & 038008 & Jiafei JTP1 & 000792 Qinghai Salt Lake Potash Company Limited & SZ & $\mathrm{P}$ & B & Covered & 2006-06-30 & 2007-06-29 & 365 & Y & 15.10 & 1 & 15.10 & 1 \\
\hline
\end{tabular}

